ALEJANDRO RAFAEL GARCIA IBARRA

\title{
DESENVOLVIMENTO DE TRANSMISSORES DE PRESSÃO DIFERENCIAL BASEADOS EM SENSORES PIEZORESISTIVOS E SAIDA ANALÓGICA DE 4-20 mA
}

São Paulo 
ALEJANDRO RAFAEL GARCIA IBARRA

\section{DESENVOLVIMENTO DE TRANSMISSORES DE PRESSÃO DIFERENCIAL BASEADOS EM SENSORES PIEZORESISTIVOS E SAIDA ANALÓGICA DE 4-20 mA}

Dissertação apresentada à Escola Politécnica da Universidade de São Paulo para a obtenção do titulo de Mestre em Ciências.

Área de Concentração:

Engenharia Elétrica

Orientador:

Prof. Dr. Edgar Charry Rodriguez

São Paulo 
Este exemplar foi revisado e corrigido em relação à versão original, sob responsabilidade única do autor e com a anuência de seu orientador.

São Paulo, de julho de 2014.

Assinatura do autor

Assinatura do orientador

\section{Catalogação-na-publicação}

Garcia Ibarra, Alejandro Rafael

Desenvolvimento de transmissores de pressão diferencial baseados em sensores piezoresistivos com saída analógica de 4-20 mA / A.R. Garcia Ibarra. -- versão corr. -- São Paulo, 2014.

$75 \mathrm{p}$.

Dissertação (Mestrado) - Escola Politécnica da Universidade de São Paulo. Departamento de Engenharia de Sistemas Eletrônicos.

1.Equipamentos de instrumentação elétrica 2.Dispositivos eletrônicos 3.Sensores eletromecânicos I.Universidade de São Paulo. Escola Politécnica. Departamento de Engenharia de Sistemas Eletrônicos II.t. 
Dedico esse trabalho a minha mãe Esperanza Ibarra Ramirez e aos meus irmãos Mauricio García Ibarra, Jota Mario García Ibarra e Charly García Ibarra pelo apoio dado na distância durante esses anos de estudo. 


\section{AGRADECIMENTOS}

Este projeto foi desenvolvido com os apoios da empresa MEMS Ltda e do grupo de pesquisa de "Microssistemas Integrados de Pressão Monolíticos e Híbridos do LSI/EPUSP”, liderado pelo Prof. Dr. Edgar Charry Rodrigues.

Agradeço ao programa "RHAE Pesquisador na Empresa" do Cnpq pelo fornecimento da bolsa de pesquisa durante o desenvolvimento deste projeto.

E agradeço também aos Laboratórios de Microeletrônica (LME) e de Sistemas Integráveis (LSI) da Escola Politécnica da Universidade de São Paulo (EPUSP) por prover as suas instalações para viabilizar a conclusão deste trabalho. 


\section{RESUMO}

Este projeto de pesquisa apresenta o desenvolvimento de protótipos de transmissores industriais de pressão do tipo diferencial piezoresistivo com saída analógica a dois fios 4-20 mA. Os dispositivos usam um DSSP (processador digital de sinal do sensor) para realizar compensação térmica nas temperaturas de $0^{\circ} \mathrm{C}$ até $80^{\circ} \mathrm{C}$ e a calibração de pressão diferencial na faixa de 0-25 bard e de pressão de linha de 0-7 barg. Os transmissores permitem a leitura de diversas variáveis industriais: pressão diferencial, pressão relativa e pressão absoluta em fluidos. Os transmissores têm um TEB (total error band) menor que 0,15 de porcentagem de escala plena.

A saída analógica dos transmissores diferenciais de pressão é caracterizada utilizando como base normas internacionais BS (British Standards). Os parâmetros avaliados nos transmissores de pressão são: a exatidão, o coeficiente térmico do offset, o coeficiente térmico do span, o total error band, e os desvios no tempo a curto e longo prazo.

Esse trabalho é resultado da parceria dada entre o Laboratório de Sistemas Integráveis da Escola Politécnica da Universidade de São Paulo (LSI/EPUSP) e a empresa MEMS - Microssistemas Integrados Híbridos de Pressão.

Palavras chave: sensor de pressão diferencial piezoresistivo, condicionamento de sinais, transmissor de pressão diferencial, exatidão, total error band. 


\section{ABSTRACT}

This research project presents the prototypes development of piezoresistive differential pressure transmitters with analog two-wire output of 4-20 mA. The devices use a DSSP (Digital Signal Processor Sensor) to achieve temperature compensation at temperatures from $0^{\circ} \mathrm{C}$ to $80^{\circ} \mathrm{C}$ and differential pressure calibration range from 0 bard to 25 bard and line pressure range from 0 barg to 7 barg. The transmitters measure several industrial variables: differential pressure, relative pressure and absolute pressure at fluids. The transmitters have a TEB (total error band) less than 0.15 percent of full scale.

The analog output of the differential pressure transmitters is characterized using British Standards-BS. The parameters evaluated in the pressure transmitters are: the accuracy, the thermal coefficient of the offset, the thermal coefficient of the span, the total error band, the start-up drift and long-term drift.

This work is the result of the academic and technological partnership between the Laboratory of Integrated Systems of the Polytechnic School of the University of São Paulo (LSI / EPUSP) and the MEMS company - Microssistemas Integrados Híbridos de Pressão Ltda.

Keywords: Piezoresistive differential pressure sensor, signal conditioning, differential pressure transmitter, accuracy, total error band. 


\section{LISTA DE ILUSTRAÇÕES}

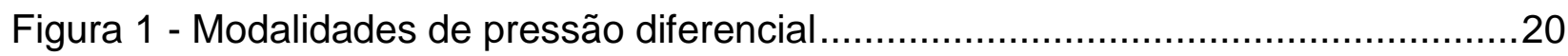

Figura 2 - Configuração do sensor de pressão diferencial (Sensors, 2008b) .................21

Figura 3 - Tipos de deflexão da membrana em um sensor de pressão diferencial.

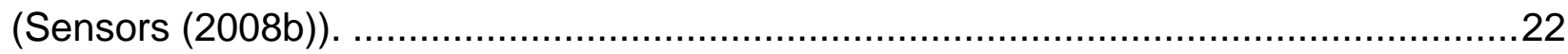

Figura 4 - Sensor de pressão diferencial unidirecional (Sensors, 2008a). ...................23

Figura 5 - Sensor de pressão diferencial bidirecional (Sensors, 2008a). ......................24

Figura 6 - Medidor de pressão diferencial usando dois sensores absolutos (Druck). ...25

Figura 7 - Layout do sensor de pressão diferencial (Firtat et al., 2007). ......................26

Figura 8 - Seção transversal do sensor de pressão (Kato et al., 2000).........................26

Figura 9 - Transdutor de pressão diferencial (Samek e Mei, 1990) ............................27

Figura 10 - Medição de estanqueidade pelo método de pressão diferencial. .................28

Figura 11 - Medição de vazão pelo método de pressão diferencial usando um tubo

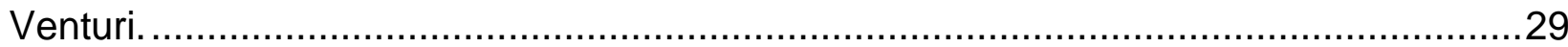

Figura 12 - Medição de nível pelo método de pressão diferencial. ...............................30

Figura 13 - Medição da velocidade do ar em túneis de vento pelo método de pressão

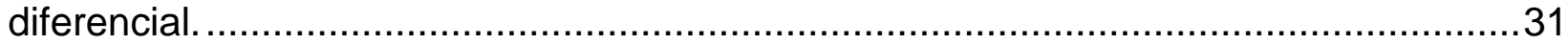

Figura 14 - Diagrama de blocos do transmissor de pressão diferencial........................37

Figura 15 - Sensor diferencial e ponte de wheatstone piezoresistiva (Microsensor,

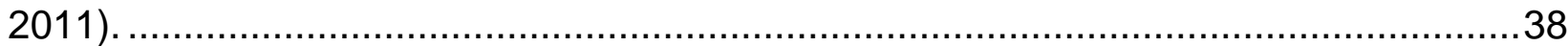

Figura 16 - Projeto do invólucro do sensor de pressão diferencial. ..............................39

Figura 17 - Diagrama funcional do MAX1464 (Integrated, 2005b). ..............................41

Figura 18 - Fonte de corrente do sensor de pressão (Luz, 2008). .............................42

Figura 19-Sensibilidade do sensor de pressão em relação a diferentes correntes de

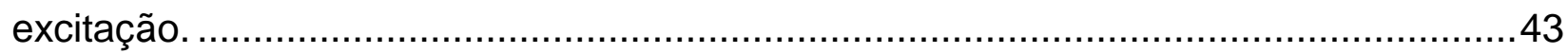

Figura 20 - Esquema do circuito tensão-corrente (Beltrán, 2005)...............................44

Figura 21 - Circuito eletrônico do transmissor de pressão diferencial. ..........................45

Figura 22 - Sistema de calibração dos transmissores de pressão. ………..................47

Figura 23 - Diagrama em blocos do algoritmo de calibração dos transmissores. ..........48 
Figura 24 - Diagrama de blocos do DSSP MAX1464

Figura 25: Soma de todos os possíveis erros usados no cálculo do TEB. (Honeywell, 2011).

Figura 26 - Equipamentos usados na caracterização dos sensores e transmissores de pressão diferencial. .58

Figura 27 - Saída do sensor vs porcentagem de entrada .59

Figura 28 - Variação do erro [\%FSO] vs Pressão diferencial [bar] vs Temperatura[ $\left[{ }^{\circ} \mathrm{C}\right] .60$ Figura 29 - Média dos erros [\%FSO] vs Pressão [bar] vs temperatura $\left[{ }^{\circ} \mathrm{C}\right]$. 62 Figura 30 - Transmissores de pressão diferencial calibrados e compensados termicamente. .65 


\section{LISTA DE TABELAS}

Tabela 1- Especificação de dados básicos do sensor de pressão diferencial.................38

Tabela 2 - Especificação das características de desempenho do sensor .......................39

Tabela 3: Variação do SPAN do sensor de pressão para diferentes correntes de excitação

Tabela 4 - Total de Ciclos de Medição. Quantidade e Localização dos Pontos de Teste (Cenelec, 2008) .53

Tabela 5 - Tensão de saída para um sensor diferencial durante 3 ciclos de pressão ....58 Tabela 6 - Tensões de saída de um sensor de pressão na faixa de temperaturas de $0^{\circ} \mathrm{C}$ até $70^{\circ} \mathrm{C}$ .59

Tabela 7 - Valores máximos da Não Linearidade, Histerese, Repetitividade .60

Tabela 8 - Correntes de saída do transmissor obtidos para três ciclos de pressão 61

Tabela 9: Média Geral dos Erros vs Pressão Diferencial vs Temperatura .....................62

Tabela 10: Coeficiente Térmico do Offset - TCO ….................................................63

Tabela 11: Coeficiente Térmico do SPAN - TCS..........................................................63

Tabela 12- Parâmetros máximos de não linearidade, histerese e repetibilidade. ..........63

Tabela 13 - Especificações do transmissor de pressão diferencial ...............................64

Tabela 14 - Desvios de start up de um transmissor de pressão para 5 min, 1 hora e 4 horas .66

Tabela 15 - Desvios na saída de corrente do transmissor de pressão a longo prazo ....67 


\section{LISTA DE SIMBOLOS}

$\begin{array}{ll}\text { MEMS } & \begin{array}{l}\text { Microelectromechanical Systems } \\ \text { eletromecânicos). }\end{array} \\ \text { mA } & \text { Mili Amperes } \\ \text { bard } & \text { Unidade de pressão diferencial } \\ \text { barg } & \text { Unidade de pressão relativa } \\ \text { OEM } & \text { Original Equipment Manufacturer } \\ \text { P } & \text { Pressão } \\ \text { T } & \text { Temperatura } \\ \text { V } & \text { Volts - Unidade de Tensão } \\ \text { SPAN } & \text { Diferença entre o valor máximo e mínimo da saída } \\ \text { Offset } & \text { Saída para a pressão mínima } \\ \text { TCO } & \text { Coeficiente térmico do zero } \\ \text { TCS } & \text { Coeficiente térmico do SPAN } \\ \text { TEB } & \text { Total error band } \\ \text { DSSP } & \text { Digital Signal Sensor Processor } \\ \text { \%FSO } & \text { Porcentagem de escala plena } \\ \text { BS } & \text { British Standards }\end{array}$




\section{SUMARIO}

1. INTRODUCÃ̃ E MOTIVACÃO

1.1 Apresentação do Problema

1.2 OBJETIVO GERAL

18

1.3 OBJETIVOS ESPECÍFICOS

18

2. REVISÃo DA LITERATURA

2.1 Pressão DifERENCIAL: FUndAMENTOS 19

2.2 SENSOR DE PRESSÃo 20

2.3 SENSOR de Pressão DiferenCIAL: FundAMENTOS 21

2.4 Tipos de Sensores de Pressão Diferencial 23

2.4.1 SENSOR DE PRESSÃo DIFERENCIAL UNIDIRECIONAL 23

2.4.2 SENSOR DE PRESSÃo DIFERENCIAL BIDIRECIONAL

2.4.3 Sensor de Pressão Diferencial Baseado em dois Sensores de Pressão Absoluta 24

2.5 FabricaÇão de Sensores de Pressão difEREnCial 25

2.6 ApliCaÇões da Medição da Pressão diferenCial 27

2.6.1 MEDIÇÃO DE ESTANQUEIDADE 27

2.6.2 MEDIÇÃo dE VAZÃo 28

2.6.3 MEDIÇÃo DE NíVEL EM TANQUES FECHADOS 30

2.6.4 MEDIÇÃo DE AR EM TÚNEIS DE VENTO 31

2.7 Efeitos de Diversas VARí́veis na SAída do SENSOR de Pressão DiferenCial 32

2.7.1 EFEITOS DA ORIENTAÇÃO 32

2.7.2 VIBRAÇÃO 33

2.7.3 ProteÇÃo ConTra Sobrepressão 33

2.7.4 EFEITOS DA PRESSÃo de LiNHA 34

2.7.5 RESPOSTA NO TEMPO 34

2.7.6 Histerese Térmica em Sensores de Pressão Diferencial 35

2.8 Condicionamento E Processamento do Sinal do Sensor de Pressão 35 


\section{CONSTRUCCÃO DO TRANSMISSOR DIFERENCIAL PIEZORESISTIVO COM SAÍDA}

3.1 HARDWARE

3.1.1 SENSOR DIFERENCIAL UTILIZADO

3.2 InVÓluCro do SENSOR de PRESSÃo DifERENCIAL

3.3 Condicionamento e Processamento do Sinal do Sensor de Pressão

3.3.2 Projeto da Fonte de Corrente do SEnSor de Pressão

3.3.3 Projeto do CONVERSOR TENSÃo-CORRENTE

3.3.4 FonTE de TENSÃo do CirCUITO Eletrônico

3.4 CALIBRAÇÃo E COMPENSAÇÃo: FUNDAMENTOS

3.4.1 Algoritmo de Calibração dos Transmissores de Pressão

3.4.2 AlgoritMo de COMPENSAÇÃo IMPlEMENTAdo nOS TranSMisSORES DE PRESSÃo

\section{CARACTERIZACÃO DOS PARÂMETROS DE SAÍDA DO SENSOR E DO}

4.1 EXATIDÃO

4.2 COEFICIENTE DE TEMPERATURA DO OFFSET (TCO)

4.3 COEFICIENTE DE TEMPERATURA DO SPAN (TCS)

4.4 TOTAL ERROR BAND - TEB

4.5 CARACTERIZAÇÃo dos SENSORES DifERENCIAIS SEM COMPENSAR E SEM CALIBRAR

4.5.1 EQUIPAMENTOS

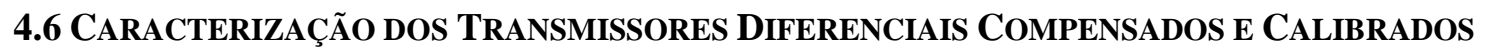

4.7 Análise dos Resultados da CaracterizaÇão dos SENSORES E dos TranSMiSSORES de Pressão Diferencial 
4.8.1 Medição do Desvio de StART-UP

4.8.1.1 Resultados

4.8.2 MediçÃo do DESVIO de LONGo Prazo 66

$\begin{array}{ll}\text { 4.8.2.1 RESUltados } & 67\end{array}$

5.

6. CONCLUSÕES $\quad 69$

7. REFERÊNCIAS $\quad 70$

8. ANEXOS $\quad 74$ 


\section{INTRODUÇÃO E MOTIVAÇÃO}

O transmissor de pressão diferencial é o dispositivo básico para medir vazão, nível e estanqueidade de fluidos na área de automação. Além disto, o transmissor de pressão diferencial tem aplicações na medição de pressões diferenciais, relativas e absolutas de fluidos. Ou seja, é um dispositivo essencial na área de automação industrial.

Atualmente o Brasil importa a maior parte dos transmissores de pressão diferencial piezoresistivos, pois estes equipamentos não são fabricados no país. A principal diferença com os produtos nacionais atuais é o tipo de sensor diferencial (capacitivo), característica que reflete diretamente no preço final do produto, pois o custo dos sensores diferenciais piezoresistivos é bem menor.

O Laboratório de Sistemas Integráveis da Escola Politécnica da Universidade de São Paulo (LSI-EPUSP) junto com uma parceria industrial (Mems (2004)) desenvolveram transmissores de pressão diferenciais OEM (Fabricante Original do Equipamento) para medir vazão, nível e estanqueidade, porém este protótipo é um dispositivo completo quando é usado na medição de pressão relativa ou absoluta, com características de baixo custo, altíssima precisão e alta confiabilidade.

O transmissor consta de um sensor de pressão diferencial piezoresistivo isolado do meio externo nas portas de entrada. O invólucro do sensor foi feito numa estrutura de aço inox o que lhe permite trabalhar com pressões de linha de até 200 barg em ambientes agressivos e não agressivos.

A compensação e a calibração ( $C \& C)$ do sensor são feitas em forma completamente digital utilizando a tecnologia DSSP (Digital Sensor Signal Processor) a qual permite atingir exatidões melhores que $0,1 \%$ de escala plena nas faixas de temperatura de $0^{\circ} \mathrm{C}$ até $80^{\circ} \mathrm{C}$. Para realizar esta $\mathrm{C} \& \mathrm{C}$ utiliza-se um algoritmo de 
aproximação por polinômios em conjunto com câmaras climáticas com controle de umidade e calibradores de pressão de altíssima exatidão (inferior a 0,01\% FSO).

O procedimento de C\&C está completamente dominado pelo grupo de pesquisa tecnológica do LSI-EPUSP, comprovado pela fabricação de diferentes tipos de transmissores de pressão piezoresistivos utilizados em aplicações de campo na indústria em geral.

O sinal do sensor já processado digitalmente é acondicionado ao padrão de corrente de 4-20mA mediante o projeto consolidado de um conversor tensão-corrente o qual também é compensado termicamente dentro do algoritmo. A compensação é tal que fornece os valores padrões (4-20 mA) permitindo assim a calibração da saída do transmissor.

Foram fabricados 10 transmissores na faixa de pressão diferencial de 0 até 25 bard e pressão de linha de 0 até 7 barg. A faixa de temperatura compensada foi de 0 $80^{\circ} \mathrm{C}$. Os transmissores foram caracterizados usando os procedimentos descritos nas normas internacionais IEC 60770 e BS 6174. A partir da caracterização foi determinada uma faixa de erro total (Total Error Band - TEB) melhor que $0,15 \%$ da escala plena (FSO). O TEB inclui os erros da histerese, repetibilidade, não linearidade, coeficiente térmico do span (TCS) e o coeficiente térmico do offset (TCO).

O documento encontra-se organizado da seguinte forma: nas seções 2.1 até 2.8 se mostra o estado da arte relacionado com os sensores de pressão diferencial e os sistemas de acondicionamento de sinal. Das seções 3 até 3.4 .2 se apresenta a fabricação do transmissor de pressão indicando-se o hardware e firmware do dispositivo. Nas seções 4 a 4.7 se detalha o processo de caracterização do TEB dos sensores e dos transmissores diferenciais utilizando como referências às normas britânicas BS 61298:2008 e BS 60770:2011. Já nas seções 4.8 até 4.8.2.2 são descritos os testes de estabilidade da saída em corrente do transmissor de pressão a curto e longo prazos tendo como base a norma BS 6174:1982. 


\subsection{ApresentaÇÃo do Problema}

Pela necessidade da empresa MEMS-Microssistemas Integrados Híbridos de pressão Ltda de fornecer ao mercado brasileiro um transmissor de pressão diferencial de alta qualidade que fosse concorrente com os equipamentos industriais comercializados atualmente no país, foi solicitado ao grupo de pesquisa do Laboratório de Sistemas Integráveis da Escola Politécnica da Universidade de São Paulo - LSI/EPUSP realizar o desenvolvimento de um protótipo de transmissor de pressão diferencial baseado nas tecnologias de sensoriamento piezoresistivo de pressão e o processamento digital de sinais DSSP.

O nosso grupo de pesquisa do LSI da EPUSP tem domínio e alta experiência sobre a tecnologia de transmissores de pressão piezoresistivos com tecnologia DSSP usando sensores de pressão relativa e absoluta. Porem ainda não tem os conhecimentos sobre a tecnologia de transmissores de pressão diferencial piezoresistivos.

Pelo anteriormente mencionado, nesse projeto será realizada uma pesquisa exploratória relacionada com as principais características da tecnologia dos transmissores de pressão diferencial assim como também será construído um protótipo industrial de transmissor de pressão diferencial piezoresistivo com comunicação analógica de 4-20 mA. Este dispositivo terá a capacidade de compensar a influencia da temperatura na leitura da pressão diferencial assim como também permitirá calibrar a leitura da saída analógica de corrente de 4-20 mA para diferentes faixas de pressão diferencial, tudo isto será desenvolvido empregando a tecnologia DSSP. 


\subsection{OBJETIVO GERAL}

Desenvolver um protótipo de transmissor de pressão diferencial industrial piezoresistivo de alta exatidão, qualidade e confiabilidade com saída analógica a dois fios 4-20 mA (de quatro a vinte miliamperes). Este transmissor terá as seguintes características:

- Faixa de pressão de linha de 0 - 7 barg.

- Faixa de pressão diferencial: 0- 25 bard

- Tipo de sensor: diferencial piezoresistivo em silício

- Exatidão: (Não-Linearidade, Histerese, repetitividade) $\leq 0,1 \%$ FSO

- Faixa de Erro Total (TEB) $\leq 0,5 \% \mathrm{FSO}$

- Faixa de temperatura compensada: $0-80^{\circ} \mathrm{C}$.

\subsection{OBJETIVOS ESPECífICOS}

- Estudar, especificar e selecionar o invólucro e o sensor de pressão diferencial piezoresistivo

- Estudar e especificar o hardware e o firmware do circuito de condicionamento e processamento do sinal do sensor de pressão diferencial piezoresistivo.

- Construir o protótipo do transmissor de pressão diferencial com comunicação analógica a dois fios de 4-20 mA

- Realizar a caracterização da faixa de total error band (TEB) para o protótipo do transmissor de pressão diferencial. 


\section{REVISÃO DA LITERATURA}

Este capítulo analisa o estado da arte relacionado com as principais características dos sensores diferenciais piezoresistivos, os diversos tipos de sensores diferenciais, assim como é feita uma descrição do processo de fabricação, e é estudada a versatilidade de aplicações de estes sensores. Também é apresentada a descrição dos sistemas de condicionamento de sinal do tipo analógico e digital usados com sensores de pressão piezoresistivos.

\subsection{Pressão Diferencial: Fundamentos}

A pressão expressa a força requerida para deter a expansão de um fluido, e esta é especificada em termos de força por unidade de área. A medição de pressão é sempre realizada a partir de um valor referencial. Dependendo do referencial utilizado, as modalidades de pressão medida são: pressão absoluta, pressão relativa, pressão de vácuo e pressão diferencial.

A pressão diferencial é a diferença em magnitude entre um valor de pressão medido e uma pressão de referência. De certo modo, as pressões absolutas e relativas podem ser consideradas tipos de pressão diferencial com o zero absoluto e a pressão atmosférica como as pressões de referência. (Sensors (2008a))

A pressão de vácuo é também um caso de medição de pressão diferencial quando a pressão absoluta medida é menor que a pressão atmosférica. A pressão de vácuo avalia o quanto a pressão está abaixo da pressão atmosférica.

$\mathrm{Na}$ medição de pressão diferencial são comparadas duas pressões $P_{1}$ e $P_{2}$, as quais devem satisfazer as condições de $P_{1}>P_{2}$ ou $P_{2}>P_{1}$.Na Figura 1 são apresentadas as modalidades de pressão diferencial em relação aos diversos tipos de referências. 


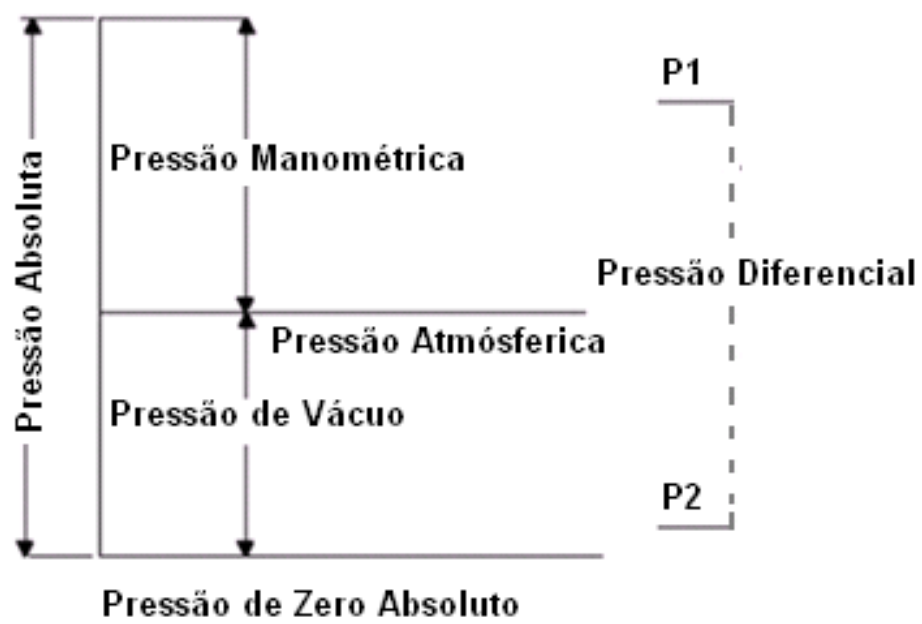

Figura 1 - Modalidades de pressão diferencial

\subsection{Sensor de Pressão}

O sensor de pressão é um dispositivo usado para medir a pressão de um fluido. Dependo da pressão correspondente, são usados os termos de pressão absoluta quando a referência é o vácuo, se denomina pressão relativa quando a referência é a pressão atmosférica e o termo diferencial é usado quando o sensor tem duas portas para medir duas pressões diferentes.

O sensor de pressão gera um sinal elétrico relacionado com a pressão que the é exercida. Este sinal é normalmente do tipo digital ou analógico.

Os sensores de pressão são usados numa grande variedade de aplicações em processos de controle e monitoramento. Os sensores de pressão também podem ser usados para indiretamente medir outras variáveis como por exemplo, a vazão de um fluido, a velocidade do ar em túneis de vento, o nível de líquidos e a estanqueidade. 


\subsection{Sensor de Pressão Diferencial: Fundamentos}

O sensor de pressão diferencial tem a mesma configuração dos sensores de pressão relativa e absoluta onde as pressões de referência são a pressão atmosférica e a pressão de zero absoluto (Sensors (2008b)). Na Figura 2 se mostra a configuração interna dum sensor de pressão diferencial piezoresistivo. Nessa figura estão sinalizadas as portas de entrada $P_{1}$ e $P_{2}$ assim como o elemento piezoresistivo colocado sobre uma membrana de silício protegido por um gel de silicone.

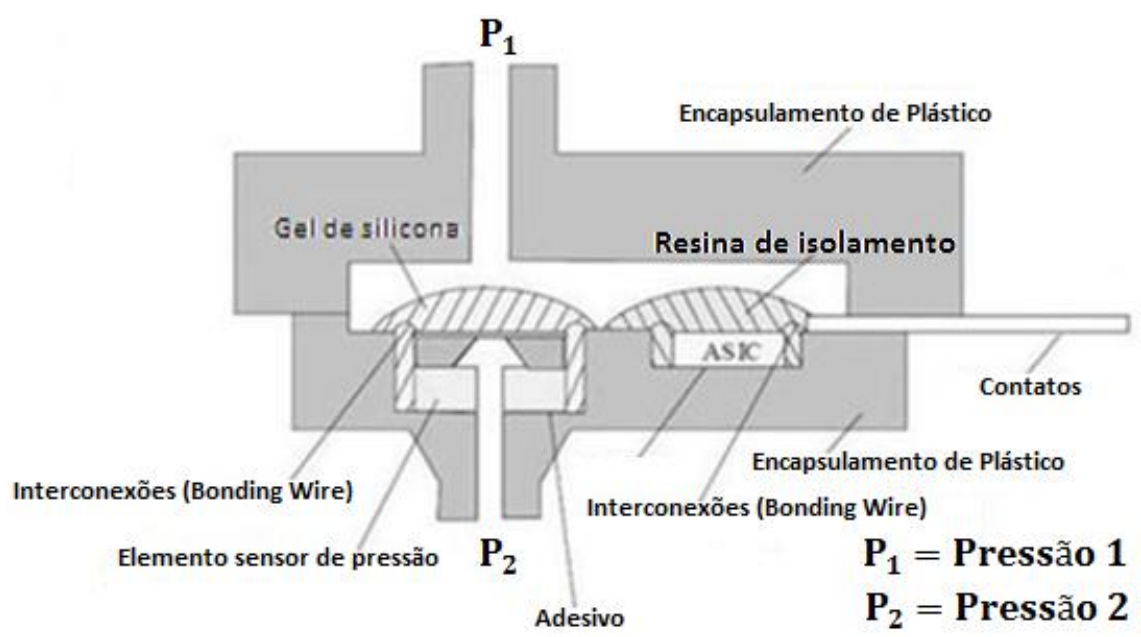

Figura 2 - Configuração do sensor de pressão diferencial (Sensors, 2008b)

Já na Figura 3 é demostrada a deflexão da membrana de um sensor diferencial nas diferentes condições de pressão. A deflexão da membrana se transforma em variações na tensão de saída do sensor. 


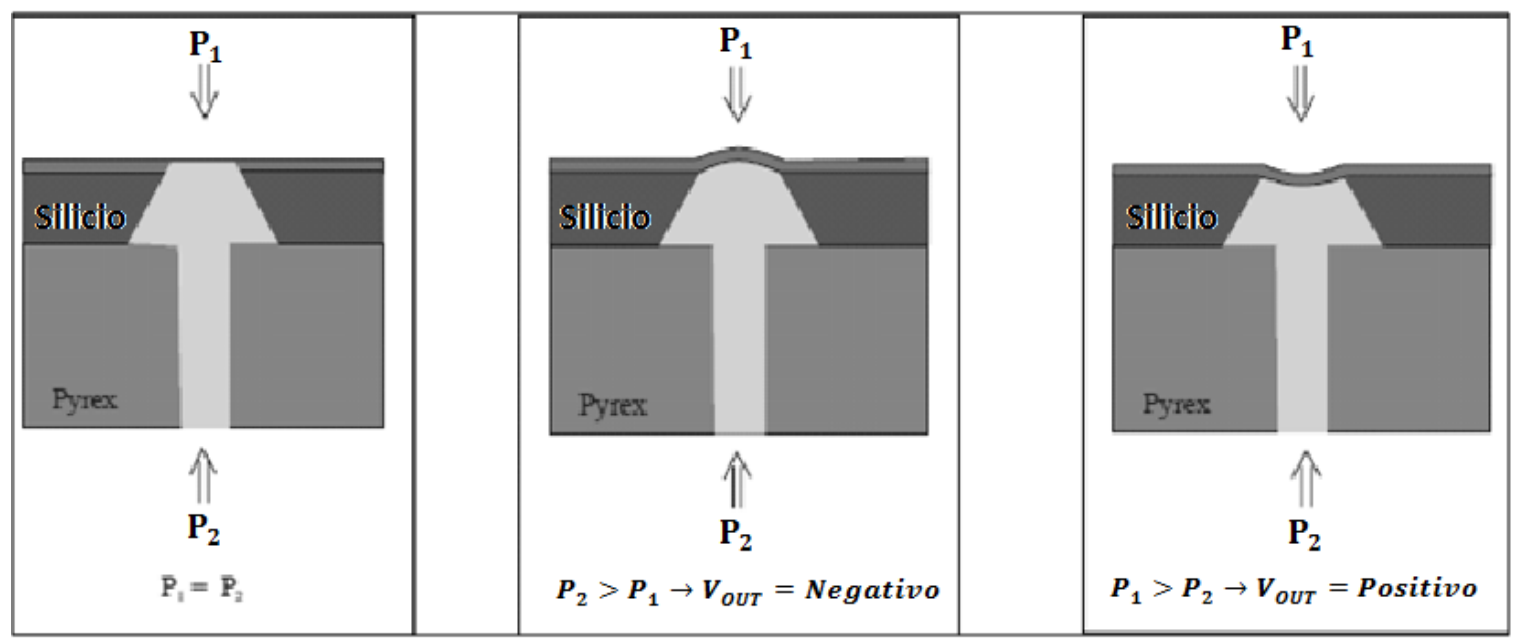

Figura 3 - Tipos de deflexão da membrana em um sensor de pressão diferencial. (Sensors (2008b)).

O funcionamento dos sensores de pressão diferencial está baseado em duas regras gerais. A primeira destas regras estabelece a máxima pressão diferencial $P_{\max }$ definida pelas características físicas do sensor (Sensors (2008b)). Esta regra está especificada pelas equações: eq.(1) e eq.(2).

$$
\begin{aligned}
& P_{1}-P_{2}<P_{\text {max }} \\
& P_{2}-P_{1}<P_{\text {max }}
\end{aligned}
$$

Onde $P_{1}$ e $P_{2}$ são as pressões aplicadas nas duas portas do sensor de pressão diferencial.

A segunda regra está relacionada com a resistência do encapsulamento do sensor a uma pressão aplicada de forma simultânea nas suas duas portas de entrada. Isto significa que tanto $P_{1}$ quanto $P_{2}$ não podem exceder certo valor de pressão como é mostrado na eq.(3). Este parâmetro $P_{\text {System }}$ é denominado como máxima pressão do sistema ou máxima pressão de linha.

$$
\boldsymbol{P}_{1}, \boldsymbol{P}_{2} \leq \boldsymbol{P}_{\text {System }}(\mathbf{3})
$$


Em alguns casos a saída do sensor de pressão não é somente proporcional à pressão diferencial, também a certo grau da pressão de linha. Este efeito é denominado de sensibilidade do sensor à pressão de linha.

\subsection{Tipos de Sensores de Pressão Diferencial}

\subsubsection{Sensor de Pressão Diferencial Unidirecional}

O sensor de pressão unidirecional mede pressões diferenciais num único sentido. Neste tipo de sensores a pressão aplicada numa porta sempre é maior que a pressão exercida na outra porta do sensor. A pressão diferencial para esta classe de sensor está expressa pela eq.(4). A deflexão da membrana num sensor de pressão diferencial unidirecional está apresentada na Figura 4.

$$
0 \leq P_{1}-P_{2} \leq P_{\text {max }} \text { (4) }
$$

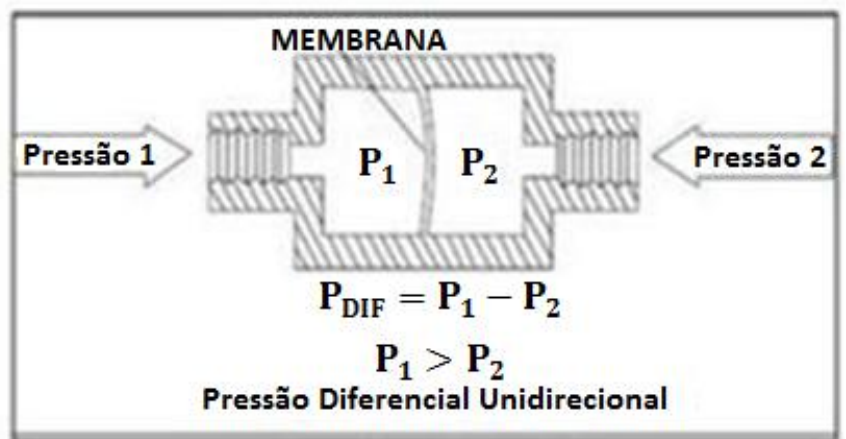

Figura 4 - Sensor de pressão diferencial unidirecional (Sensors, 2008a). 


\subsubsection{Sensor de Pressão Diferencial Bidirecional}

Este tipo de sensor de pressão tem a capacidade de medir pressões diferenciais positivas e negativas. Isto significa que a pressão em uma das portas de entrada pode ser maior ou menor que a pressão aplicada na outra porta do sensor (Sensors (2008a)). As pressões P1 e P2 aplicadas no sensor bidirecional devem cumprir as condições da eq.(5).

$$
\boldsymbol{P}_{\text {min }} \leq\left|\boldsymbol{P}_{1}-\boldsymbol{P}_{2}\right| \leq \boldsymbol{P}_{\text {max }}
$$

Onde $P_{\min }$ e $P_{\max }$ são as pressões mínima e máxima da faixa de pressão do sensor diferencial. Na Figura 5 é mostrada a deflexão da membrana de um sensor bidirecional.

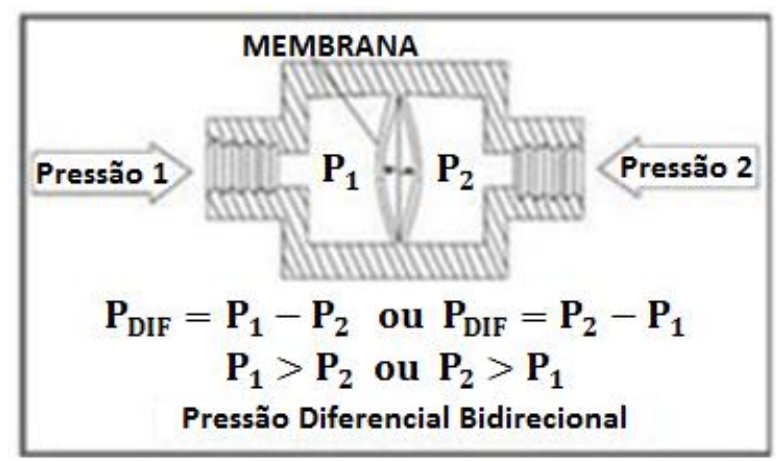

Figura 5 - Sensor de pressão diferencial bidirecional (Sensors, 2008a).

\subsubsection{Sensor de Pressão Diferencial Baseado em dois Sensores de Pressão} Absoluta

Este sensor de pressão diferencial emprega dois sensores de pressão absoluta e a saída em tensão dele é gerada de forma indireta. Na Figura 6 se mostra este tipo de sensor que é usado em aplicações que requerem alta pressão de linha. Nesta classe de 
sensor a medição da pressão diferencial precisa ser maior que o $5 \%$ da pressão de linha (Druck).

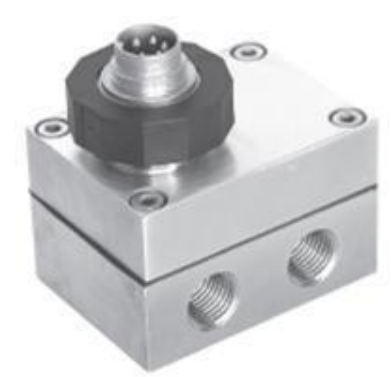

Figura 6 - Medidor de pressão diferencial usando dois sensores absolutos (Druck).

$\mathrm{Na}$ eq.(6) se apresenta a relação do erro de pressão diferencial deste tipo de medidores.

$$
\begin{gathered}
\text { Erro de pressão } \\
\text { diferencial (\%FSo) }
\end{gathered}=\underset{\text { Ee linha (\%FSo) }}{\text { Erro da pressão }} * \frac{\text { Faixa de pressão de linha }}{\text { Faixa de pressão diferencial }}(6)
$$

\subsection{Fabricação de Sensores de Pressão Diferencial}

No instituto nacional de pesquisa e desenvolvimento em micro tecnologias de Bucarest (Firtat et al., 2007) foi simulado, fabricado e testado um sensor de pressão diferencial MEMS com faixa de pressão de 0-400 mbard. Este sensor usa uma fina membrana elástica de silício e quatro piezoresistores difundidos com boro organizados numa estrutura de ponte de Wheatstone como se mostra na Figura 7. O principio de trabalho do sensor está baseado no efeito piezoresistivo que consiste em variações da corrente de saída do sensor devido à deformação da membrana de silício pela aplicação de uma pressão externa. 


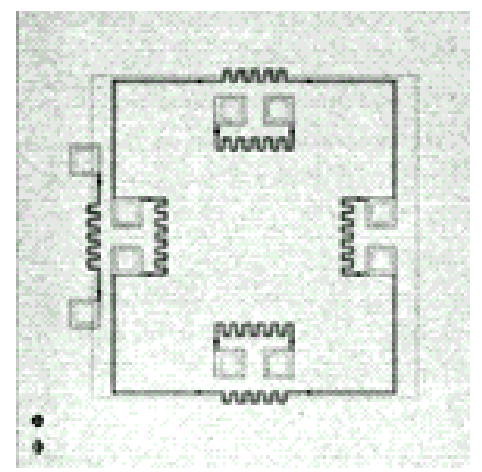

Figura 7 - Layout do sensor de pressão diferencial (Firtat et al., 2007).

No Departamento de Engenharia Mecânica da Universidade de Tóquio (Kato et al., 2000) foi fabricado um sensor de pressão diferencial usando duas membranas elásticas com piezoresistores arranjados sob a forma de ponte de Wheatstone. O sensor tem portas laterais para o ingresso da pressão, assim como estruturas projetadas para proteção contra sobre pressões. As duas pontes de piezoresistores trabalham de forma complementar onde a tensão resultante é a diferença das tensões de saída das duas pontes. Neste trabalho mostra-se que através desta estrutura de duas pontes de piezoresistores é melhorada a linearidade do sensor e são diminuídos os erros causados pelas variações da temperatura e da pressão de linha. Na Figura 8 é mostrado o corte transversal do sensor diferencial desenvolvido.

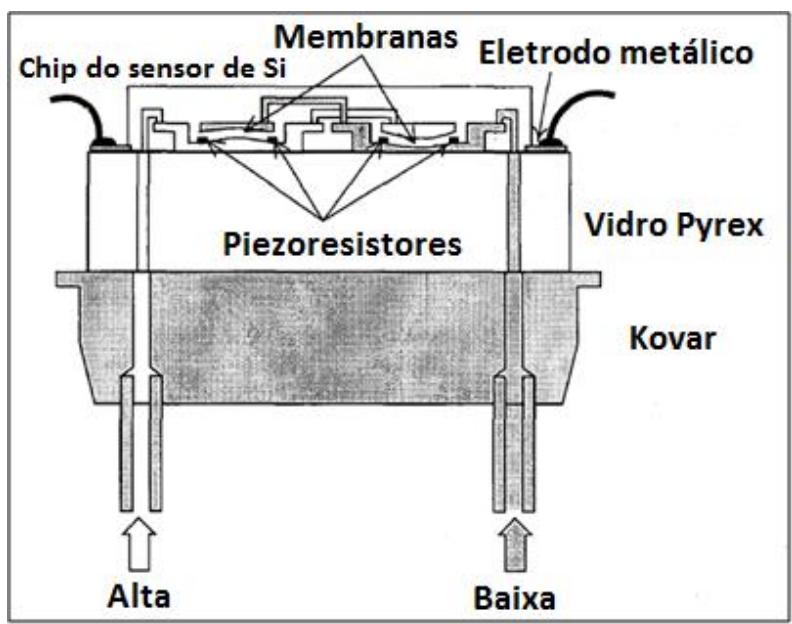

Figura 8 - Seção transversal do sensor de pressão (Kato et al., 2000).

Pesquisadores das indústrias IMO (Samek e Mei, 1990) fabricaram um transdutor de pressão diferencial wet/wet no qual a membrana do sensor está em contato direto com 
o meio através de um diafragma de isolamento. O sensor utiliza quatro piezoresistores para a medição da pressão e mais um resistor para a medição de temperatura. Este sensor e uma placa eletrônica de compensação conformam o transdutor de pressão diferencial como é mostrado na Figura 9.

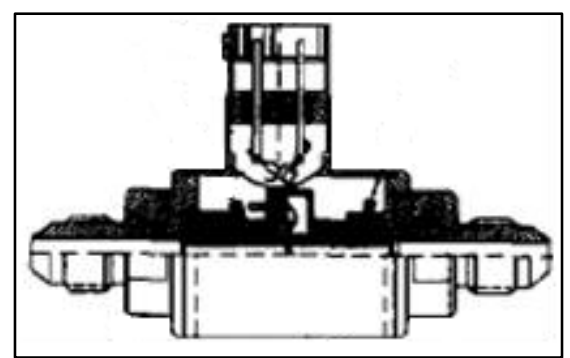

Figura 9 - Transdutor de pressão diferencial (Samek e Mei, 1990).

\subsection{Aplicações da Medição da Pressão Diferencial}

A medição de pressão diferencial é usada de forma indireta para medir outras variáveis físicas de tipo industrial tais como estanqueidade, vazão e nível em tanques fechados. Estas aplicações são explicadas logo a seguir.

\subsubsection{Medição de Estanqueidade}

A estanqueidade é a propriedade que verifica se um produto ou peça está ou não com vazamento a uma determinada pressão aplicada. O produto pode ser um recipiente plástico, uma válvula, uma torneira, o tanque de combustível de um carro, entre outros. A estanqueidade é uma etapa importante no processo do controle da qualidade de produtos.

A verificação da estanqueidade pela queda de pressão baseia-se na alteração da pressão interna do produto em teste, num período determinado de tempo. Esta variação pode ser medida por um sensor simples ou um sensor diferencial. No segundo caso, a 
pressão de teste é aplicada ao produto e a uma peça de referência que têm volumes iguais. O reservatório de referência deve ser estanque. Mede-se então a diferença de pressão entre o produto em teste e o reservatório de referência. Como se mede diretamente a diferença de pressão, pode-se chegar a uma sensibilidade e estabilidade muito maiores se comparado à detecção por sensor simples (Qing et al. (2010)). A relação de estanqueidade e pressão diferencial é dada pela eq.(7).

$$
\boldsymbol{Q}=\frac{\boldsymbol{V} * \Delta \boldsymbol{P}}{\Delta \boldsymbol{t}}
$$

Onde $\mathrm{Q}$ é a estanqueidade, $\mathrm{V}$ é o volume da peça de teste, $\Delta P$ é a queda de pressão diferencial, e $\Delta t$ é o tempo de detecção da estanqueidade. Na Figura 10 é mostrado o modelo usado para medir estanqueidade pelo método de pressão diferencial.

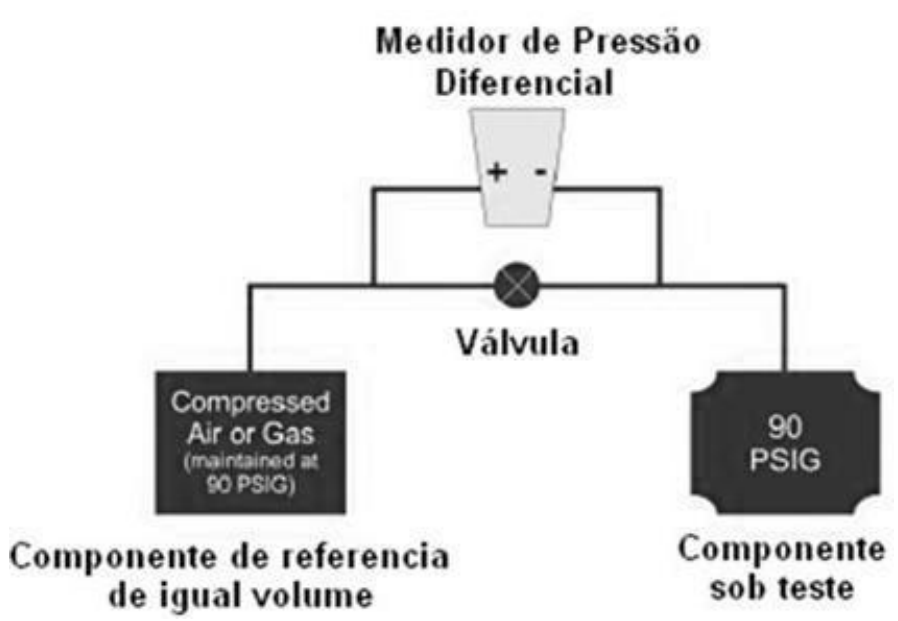

Figura 10 - Medição de estanqueidade pelo método de pressão diferencial.

\subsubsection{Medição de Vazão}

A vazão é a quantidade volumétrica de determinado fluido que passa por uma determinada seção de um conduto por uma unidade de tempo. Ou seja, vazão é a rapidez com a qual uma certa quantidade de fluido atravessa uma tubulação. 
A medição de pressão diferencial através de um obstáculo numa tubulação (placa de orifício, tubo Venturi, tubo Pitot, bocal) é um dos métodos mais usados na medição de vazão. Os medidores de vazão são compostos de um elemento primário e um elemento secundário. O elemento primário está associado com a própria tubulação, interferindo no escoamento e proporcionando um diferencial de pressão. O elemento secundário é o responsável pela leitura desta pressão e consiste basicamente dum medidor de pressão diferencial, ver Figura 11.

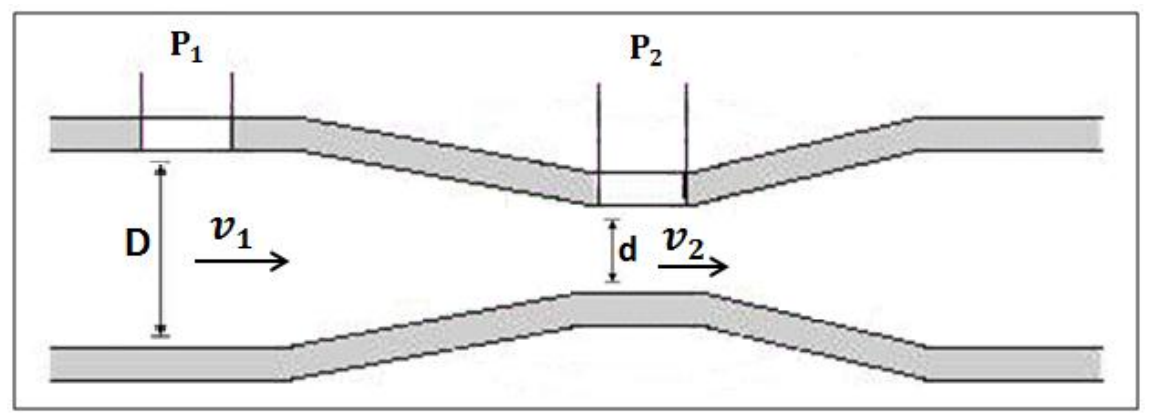

Figura 11 - Medição de vazão pelo método de pressão diferencial usando um tubo Venturi.

Os medidores de vazão por pressão diferencial baseiam seu funcionamento na equação de Bernoulli, como se mostra na eq.(8). Nesta relação a vazão é proporcional ao diferencial de pressão gerado pela aceleração do fluido que atravessa a restrição colocada dentro duma tubulação (Iso, 2003).

$$
Q_{m}=\frac{C}{\sqrt{1-\beta^{4}}} \frac{\pi d^{2}}{4} \varepsilon * \sqrt{2 \Delta P \rho_{1}}
$$

Onde:

$Q_{m}:$ vazão

C: Coeficiente de descarga

$\beta$ : relação de diametros $(d / D)$

$\varepsilon:$ Coeficiente de expansão do fluido

$\Delta P$ : Pressão Diferencial

$\rho_{1}$ : densidade do fluido 


\subsubsection{Medição de Nível em Tanques Fechados}

A medição de nível em tanques fechados é um exemplo de aplicação indireta da leitura da pressão diferencial. A medição de nível é usada em tanques selados contra a influência da pressão atmosférica. A pressão diferencial em tanques fechados aumenta ou diminui dependo do nível do fluido que se encontra dentro (Boisvert, 2006). Esta mudança da pressão diferencial tem uma relação direta com o nível do fluido, ver Figura 12.

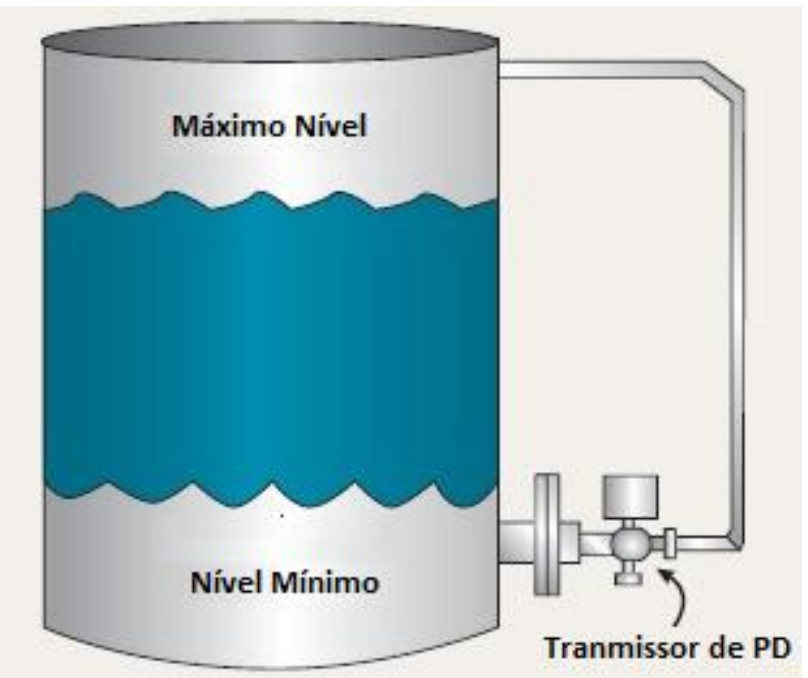

Figura 12 - Medição de nível pelo método de pressão diferencial.

A medição de nível pelo método de pressão diferencial é dada pela eq.(9).

$$
\boldsymbol{h}=\frac{\Delta \boldsymbol{P}}{\boldsymbol{\rho} * \boldsymbol{g}}(\mathbf{9})
$$

Onde:

$h=$ nível do líquido.

$\Delta P=$ pressão diferencial.

$\rho=$ densidade do líquido.

$g=$ aceleração da gravidade. 


\subsubsection{Medição de Ar em Túneis de Vento}

Aplicações com túneis de vento requerem medidores de pressão diferencial com alta exatidão e rápida resposta no tempo que permitam medir mudanças na velocidade do ar. Por meio dos medidores de pressão diferencial é possível calcular a rapidez do ar sobre um avião, medir o fluxo de ar sobre um automóvel, ou também ajudar na determinação da curvatura ótima das asas de uma turbina eólica.

Estas aplicações dos medidores de pressão diferencial são confiáveis e precisas quando o medidor é usado em conjunto com um elemento de medição primário, como por exemplo, o tubo pitot (Cavalieri.). Na Figura 13 se mostra um medidor de pressão diferencial usado para calcular a velocidade do ar num túnel de vento. A eq.(10) apresenta a dependência da variável "velocidade do ar" com relação à pressão diferencial.

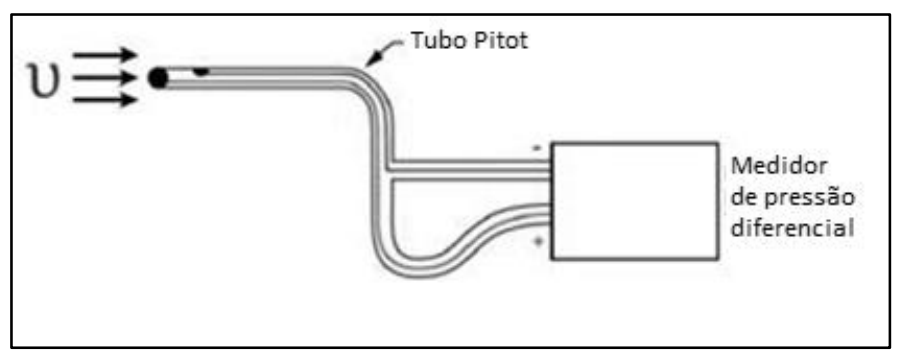

Figura 13 - Medição da velocidade do ar em túneis de vento pelo método de pressão diferencial.

$$
v=\sqrt{\frac{2 * \Delta P}{\rho}}
$$

Onde:

$v=$ velocidade do ar

$\Delta P=$ pressão diferencial

$\rho=$ densidade do ar 


\subsection{Efeitos de Diversas Variáveis na Saída do Sensor de Pressão Diferencial}

\subsubsection{Efeitos da Orientação}

A instalação incorreta ou até mesmo a manutenção de um medidor de pressão pode causar uma mudança de orientação do equipamento. Isto é conhecido como o efeito de orientação o qual tem sido tradicionalmente um problema em diversas tecnologias de sensores de pressão. Mesmo sensores de pressão instalados corretamente podem sofrer marginalmente o efeito da orientação. Este efeito é devido a que em uma unidade que é rotacionada $180^{\circ}$ indo de uma gravidade positiva até uma negativa, causa uma mudança em gravidade de $2 \mathrm{~g}$. Em função disto o sensor não pode diferenciar entre o peso gerado pela gravidade e a pressão que the é aplicada através das portas de pressão. Desta forma é combinado o efeito do peso gravitacional com a pressão aplicada, o que leva à leitura de um sinal de saída errado (Cavalieri.)

O efeito da orientação pode ser considerado muito ruim em sensores que usam óleo de silicone ou algum líquido de preenchimento, dado que o peso gerado é a soma tanto do diafragma como também do liquido que preenche o sensor. Deste modo não é possível estabelecer a pressão real de saída e será medido um valor errado de pressão.

Os fabricantes de medidores de pressão frequentemente especificam a orientação do dispositivo quando este é calibrado, e em algumas circunstâncias o fabricante pode especificar a quantidade de offset a se esperar devido a uma mudança na orientação do equipamento. 


\subsubsection{Vibração}

Vibrações de baixa frequência transmitidas por equipamentos tais como motores ou ventiladores que ficam perto de sensores de pressão podem influenciar a orientação destes. Por exemplo, o liquido de preenchimento dum sensor pode captar as vibrações de baixa freqüência e transmitir uma carga inercial ao diafragma do sensor o qual é interpretado erradamente como uma medição de pressão (Cavalieri.).

Para evitar o efeito da vibração, os medidores de pressão precisam ser colocados em áreas afastadas dos equipamentos que geram estas vibrações. Do mesmo modo, se a porta de referência for ventilada, esta precisa ser direcionada a uma área sem a influência do ruído gerado por vibrações acústicas ou pelo vento.

\subsubsection{Proteção Contra Sobrepressão}

Proteção por sobrepressão positiva e negativa tem sido e continua sendo um aspecto relevante para os fabricantes de medidores de pressão diferencial usados principalmente na detecção de estanqueidade. As proteções relativas à sobrepressão são necessárias em aplicações de medição de pequenas taxas de estanqueidade onde a pressão diferencial é baixa e a pressão de linha é muito alta.

Infelizmente nas condições antes citadas e pela influencia da sobrepressão, o medidor pode requerer recalibração e se tornar inútil. A última geração de medidores de pressão tem abordado estas questões. Como resultado os medidores de pressão atualmente são muito mais robustos, e consideravelmente mais tolerantes aos eventos da sobrepressão nas direções positiva e negativa. Esta é uma importante e nova característica. Medidores com proteção adequada em ambas as direções são apropriados para aplicações no qual eventos de sobrepressão acidental ou necessidade 
de uma alta estanqueidade possam acontecer. Se isto ocorrer, estes tipos de sensores continuarão funcionando (Cavalieri.)

\subsubsection{Efeitos da Pressão de Linha}

Em conjunto com a sobrepressão, mudanças na pressão de linha podem ser um problema, especialmente nas aplicações de estanqueidade onde a pressão de linha é elevada. A pressão de linha é a pressão absoluta aplicada de forma simultânea nas portas do medidor. Algumas mudanças na pressão de linha podem produzir pequenos estresses que induzem a variações na geometria do medidor. Estes estresses modificam a resposta da calibração, afetando o zero e a faixa de medição (span) do dispositivo. A última geração de medidores tem sido projetada para diminuir a quantidade de estresse gerada pela pressão de linha aplicada no medidor (Cavalieri.)

\subsubsection{Resposta no Tempo}

Alta resposta no tempo é outro importante fator, especialmente para o controle de pressão e aplicações com túneis de vento. A resposta no tempo de um medidor é inicialmente determinada pela tecnologia do elemento sensor e sua eletrônica.

A necessidade de uma rápida resposta é dependente da aplicação. Por exemplo, em túneis de vento onde são medidas as mudanças dinâmicas da velocidade do ar, o sinal de saída do medidor deve variar com a velocidade, requerendo-se para isto de rapida resposta no tempo. Uma resposta de 10-80 milissegundos é tipicamente aceitável em detecção de vazamento e aplicações de túneis de vento (Cavalieri.). 


\subsubsection{Histerese Térmica em Sensores de Pressão Diferencial}

Nos medidores de pressão diferencial é esperado que estes forneçam uma tensão ou corrente de saída que seja uma resposta à pressão aplicada independente de outros fatores como a temperatura. Alguns medidores de pressão têm uma instabilidade na tensão de saída com a temperatura o que degrada o desempenho do medidor. Qualquer incompatibilidade entre o elemento sensor e o empacotamento pode gerar facilmente estresse no sensor e causar deslocamentos da tensão de saída e histerese térmica durante os ciclos de temperatura. A histerese térmica que ocorre dentro de uma hora de exposição é denominada de histerese de curto tempo. Alguns desvios podem acontecer depois de vários dias os quais são chamados de deriva de longo prazo (Albert Chiou (2005)).

\subsection{Condicionamento e Processamento do Sinal do Sensor de Pressão}

Os circuitos de condicionamento de sinais são utilizados com o objetivo de compensar e calibrar os sensores de pressão piezoresistivos, eliminar as variações dos seus parâmetros com a temperatura e ajustar aqueles parâmetros que diferem do seu valor de projeto. Na literatura tem sido reportada grande variedade de circuitos de condicionamento de sinal com diferentes características e graus de complexidade.

Atualmente existem varias formas de realizar o condicionamento do sinal proveniente dos sensores. Entre as mais utilizadas se encontram as que usam técnicas puramente analógicas, baseadas principalmente no uso de redes resistivas, amplificadores operacionais e diodos. (Gomes (2009)), (Boujamaa et al. (2010))

Outros circuitos de condicionamento de sinal amplamente utilizados são os que pertencem ao grupo de Analog Sensor Signal Processor (ASSP) (Guoxiaobing (2008)), (Jorge Ramírez Beltrán (2002)). Estes dispositivos se caracterizam principalmente por 
manter o sinal proveniente do sensor em formato analógico e realizar a correção da sensibilidade e do offset utilizando amplificadores de ganho programável (PGA), conversores digitais - analógicos (DAC) e memórias não voláteis para gravar os coeficientes de correção.

Uma das formas de uso recente de condicionar os sinais provenientes de sensores é mediante a utilização de Digital Sensor Signal Processor (DSSP) (Philip C. et al. (2010)), (Chuan e Chen (2010)). Estes dispositivos digitalizam o sinal utilizando um $A D C$, o condicionam e depois o convertem ao formato analógico mediante um DAC ou o enviam através de uma saída digital. As vantagens que oferecem estes dispositivos estão estreitamente relacionadas com a variedade de opções que fornece a compensação digital como também a grande exatidão que é possível obter na sua saída.

Dadas as vantagens dos circuitos de condicionamento do sinal baseados em DSSP, foi selecionado para desenvolver este projeto o Chip DSSP MAX1464. Sua implementação é mostrada em detalhe na seção 3.3.1 


\section{CONSTRUÇÃO DO TRANSMISSOR DIFERENCIAL PIEZORESISTIVO COM SAÍDA ANALÓGICA DE 4-20 mA}

O transmissor é composto por um sensor diferencial piezoresistivo excitado por corrente e com saída em tensão. O sensor tem uma faixa de pressão diferencial de 0 até 35 bard e pressão de linha de 0 até 200 barg. Através de um circuito eletrônico e de um processo de compensação e calibração o transmissor é compensado para as temperaturas de 0 até $80^{\circ} \mathrm{C}$ e calibrado na faixa de pressão diferencial de 0 até 25 bard e de pressão de linha de 0 até 7 barg. $O$ condicionamento e o processamento digital do sinal de saída do sensor diferencial serão desenvolvidos dentro de um sistema DSSP. Esse condicionamento e processamento do sinal estarão constituídos de três etapas: conversão analógica/digital, compensação e calibração em temperatura e conversão digital/analógica. O sinal de saída em corrente de 4-20 mA é gerado por uma fonte de corrente controlada por tensão. O diagrama de blocos do transmissor de pressão diferencial é apresentado na Figura 14.

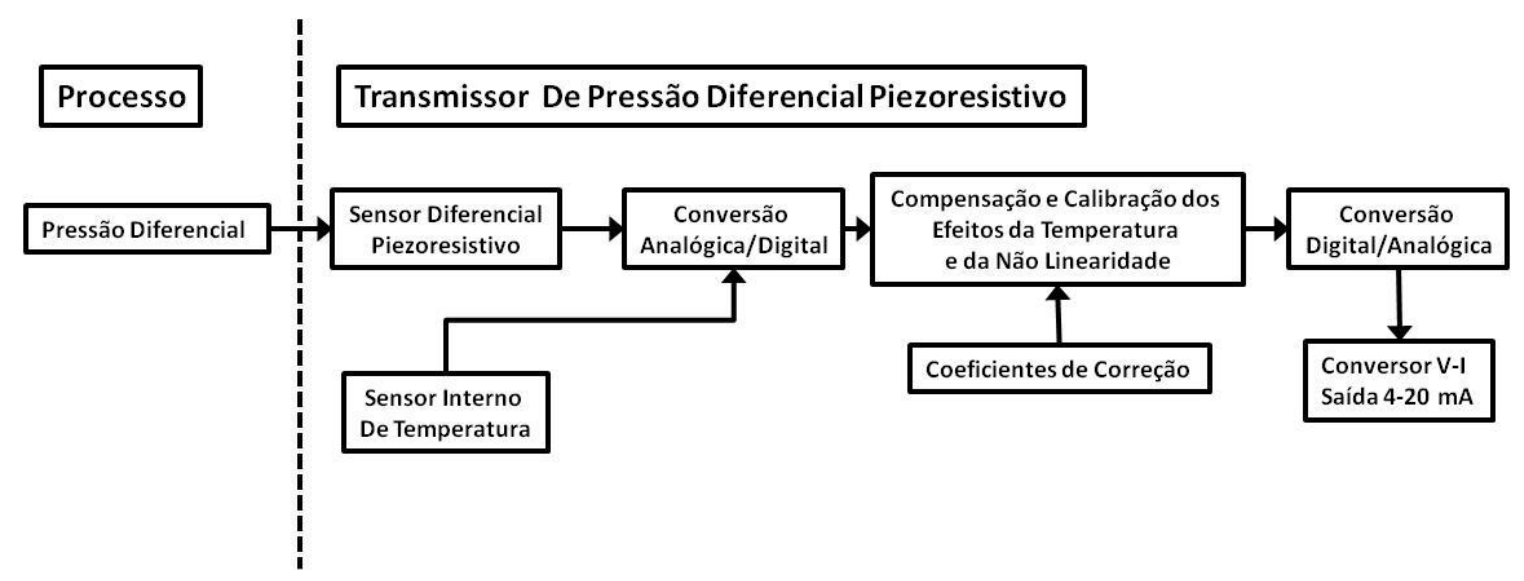

Figura 14 - Diagrama de blocos do transmissor de pressão diferencial. 


\subsection{Hardware}

\subsubsection{Sensor Diferencial Utilizado}

Para o desenvolvimento do transmissor foi selecionado um sensor de pressão diferencial piezoresistivo unidirecional o qual se mostra na Figura 15. A construção integrada do sensor fornece pressão de linha de até 200 barg, grande estabilidade e confiabilidade. Os lados de baixas e altas pressões são protegidos por diafragmas isolantes feitos em aço, inox o que permite ao sensor trabalhar em ambientes agressivos. Internamente a pressão diferencial aplicada é transmitida a uma ponte de Wheatstone piezoresistiva por meio de um óleo de silicone. (Microsensor (2011)).

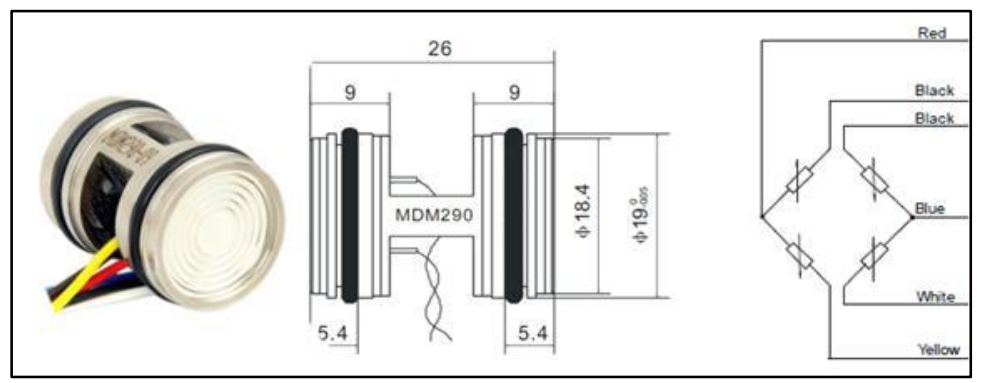

Figura 15 - Sensor diferencial e ponte de wheatstone piezoresistiva (Microsensor, 2011).

Nas tabelas 1 e 2 são especificadas as faixas de pressão e as características de exatidão do sensor de pressão diferencial. Estas características e o baixo custo deste sensor foram os critérios da sua seleção na fabricação do transmissor de pressão diferencial.

Tabela 1- Especificação de dados básicos do sensor de pressão diferencial

\begin{tabular}{lc}
\hline \multicolumn{1}{c}{ Item } & Valor. \\
\hline Faixa de Pressão Diferencial & $0-35$ bard \\
Faixa de Pressão Estática & $0-200$ barg \\
Corrente de Alimentação & $1,5 \mathrm{~mA}$ \\
Sobre-Pressão Positiva & $70 \mathrm{bard}$ \\
Sobre-Pressão Negativa & 10bard \\
\hline
\end{tabular}


Tabela 2 - Especificação das características de desempenho do sensor

\begin{tabular}{lcccc}
\hline Item & Val. Min. & Valor Typ. & Valor Max. & Unidades \\
\hline Não linearidade & & $\pm 0,15$ & $\pm 0,25$ & $\%$ FSO,BFSL \\
Histerese & & $\pm 0,05$ & $\pm 0,075$ & $\%$ FSO \\
Repetitividade & & $\pm 0,05$ & $\pm 0,075$ & $\%$ FSO \\
Estabilidade & $\pm 0,3$ & $\pm 0,5$ & $\%$ FSO/Ano \\
Erro Térmico do Zero & & $+1,0$ & 1,2 & $\%$ FSO, @25c \\
Erro Térmico do SPAN & & 1,0 & 1,2 & $\% F S O, @ 25 \mathrm{c}$ \\
Offset & 190,4 & & 3 & $\mathrm{mV}$ \\
SPAN & 3 & & 191,5 & $\mathrm{mV}$ \\
Imp. De Entrada & 3,5 & & 8 & $\mathrm{k} \Omega$ \\
Imp. De Saída & & & & $\mathrm{k} \Omega$ \\
\hline
\end{tabular}

\subsection{Invólucro do Sensor de Pressão Diferencial}

O projeto do invólucro do sensor de pressão foi baseado na norma internacional BS EN 61518:2001, a qual especifica os materiais e dimensões dos diferentes tipos de invólucros usados com sensores diferenciais piezoresistivos. Este invólucro foi fabricado por uma empresa nacional permitindo ter um produto mecânico de altíssima qualidade e baixo custo. Na Figura 16 temos o invólucro feito numa estrutura de aço inox AISI 304 com conexões ao processo de 1/4. NPT. As dimensões deste foram: $8 \mathrm{~cm}$ de comprimento, $3 \mathrm{~cm}$ de diâmetro e $5 \mathrm{~cm}$ de altura. Este invólucro permite trabalhar com pressões de linha de até 200 barg e a sua função é isolar o sensor de ambientes agressivos como gases e líquidos corrosivos. (Cenelec (2001))

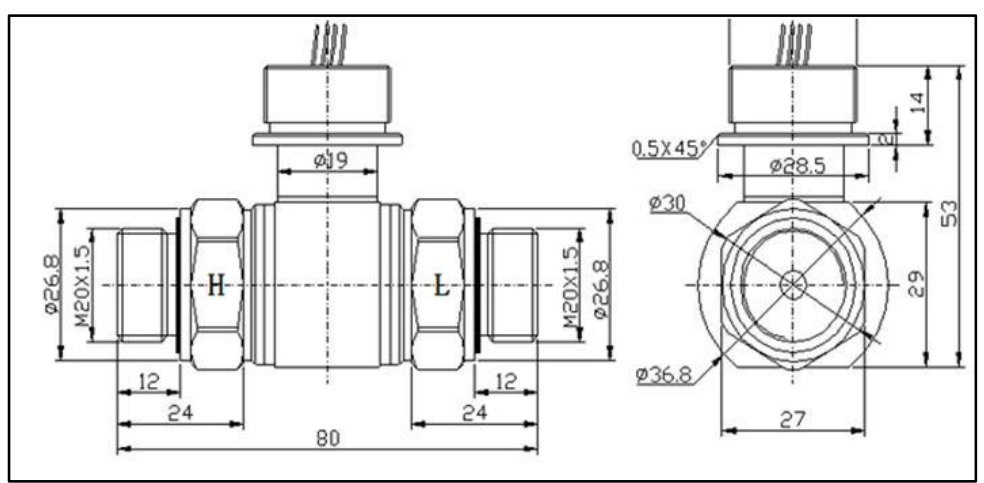

Figura 16 - Projeto do invólucro do sensor de pressão diferencial. 


\subsection{Condicionamento e Processamento do Sinal do Sensor de Pressão}

O condicionamento de sinais do sensor de pressão usado neste projeto é feito com técnicas DSSP. O circuito de condicionamento e processamento do sinal está baseado no sistema DSSP MAX1464 que permite a compensação das influências da temperatura sobre o sinal de pressão. No projeto do transmissor usando o DSSP, além de colocar os componentes externos de este dispositivo (Integrated (2005b))., serão projetadas: a fonte de corrente que alimenta o sensor, o conversor tensão-corrente que gera a saída 4-20 mA e a fonte de alimentação de todo o circuito.

\subsubsection{DSSP MAX1464}

O MAX1464 é um chip ASIC (Application Specific Integrated Circuit) de condicionamento de sinal altamente integrado, de baixo consumo de potência e com vários canais de baixo ruído. O MAX1464 pode ser usado com sensores de saída única ou de saída diferencial com sensibilidades desde 1mV/V até 1V/V (Luz (2006)). Ele oferece amplificação do sinal do sensor, calibração, linearização do sinal e compensação de temperatura que permitem um desempenho global abordando a repetitividade inerente ao sensor sem necessidade de nenhum componente externo de ajuste. (Integrated (2005b)). Na Figura 17 pode-se observar o diagrama funcional do MAX1464. Abaixo são enumeradas as suas características mais importantes:

- CPU de 16 bits. Amplificação programável, calibração, linearização e compensação de temperatura;

- ADC de 16 bits com dois canais diferenciais ou quatro canais com única entrada;

- Pode ser usado com sensores de sensibilidade desde $1 \mathrm{mV} / \mathrm{V}$ até $1 \mathrm{~V} / \mathrm{V}$;

- Dois canais de saída DAC de 16 bits ou PWM de 12 bits;

- Memória Flash de 4 kB para o código e os coeficientes; 
- Memória FLASH de 128 Bytes para informações de usuário;

- Uma interface de comunicações SPI;

- Duas portas de entrada/saída de uso geral (GPIO);

- Sensor de temperatura integrado;

- Bloco de dois amplificadores operacionais;

- Ganho e zero de entrada do sensor programáveis;

- Taxa de amostragem e resolução do sensor programável;

- Opera com uma fonte única de 5.0V.

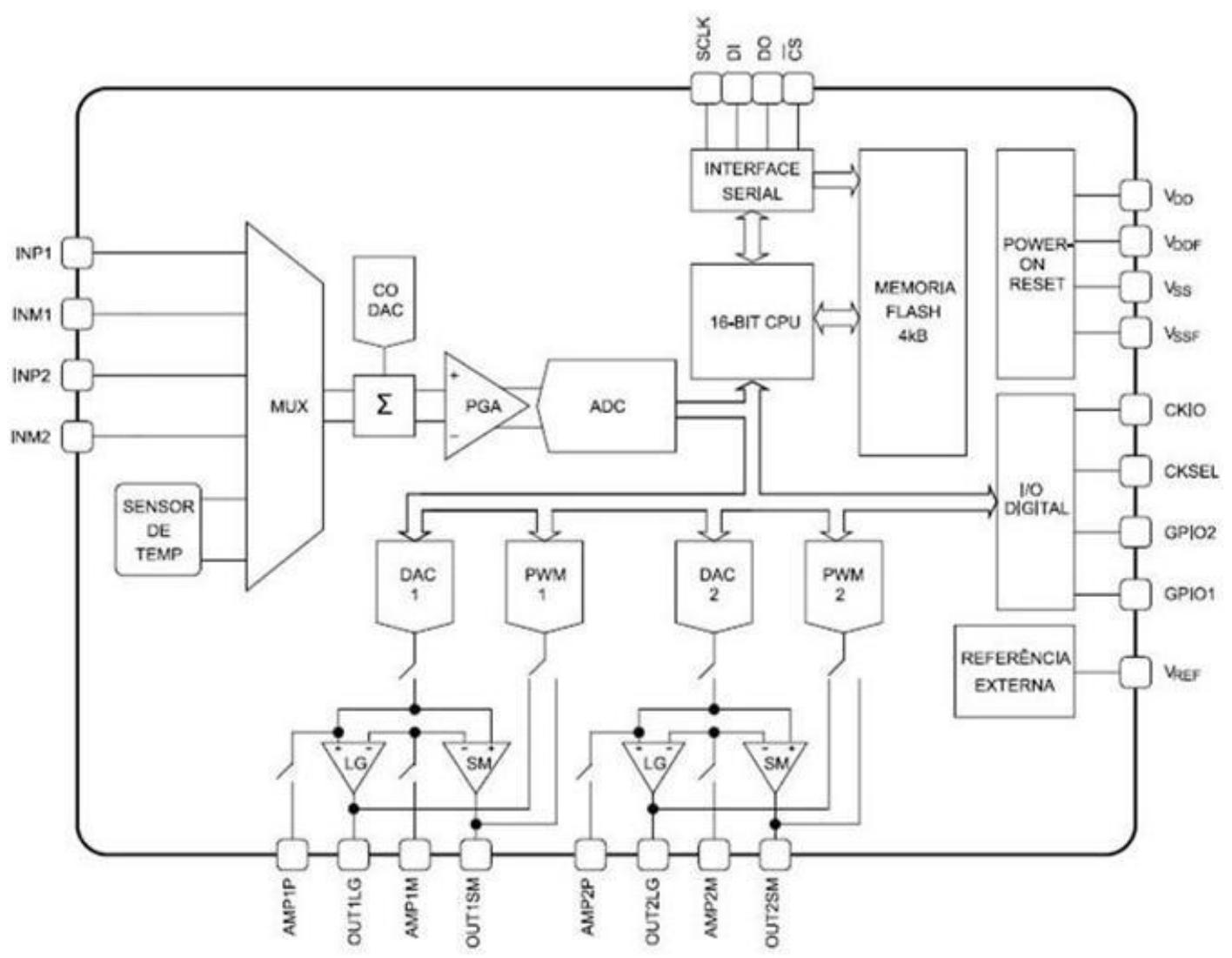

Figura 17 - Diagrama funcional do MAX1464 (Integrated, 2005b). 


\subsubsection{Projeto da Fonte de Corrente do Sensor de Pressão}

Para a fonte de corrente que alimenta o sensor usa-se um dos amplificadores operacionais que disponibiliza o MAX1464, como demonstrado na Figura 18. Projetouse a fonte de corrente de alimentação de $I_{\text {exc }}=230 u A$ de forma tal que a tensão de saída da ponte esteja dentro da faixa de sensibilidade de entrada do MAX1464 e que não seja tão alto que comprometa o consumo de corrente de todo o circuito, que tem que ser menor que 4 mA. (Luz (2008)), (Integrated (2004)).

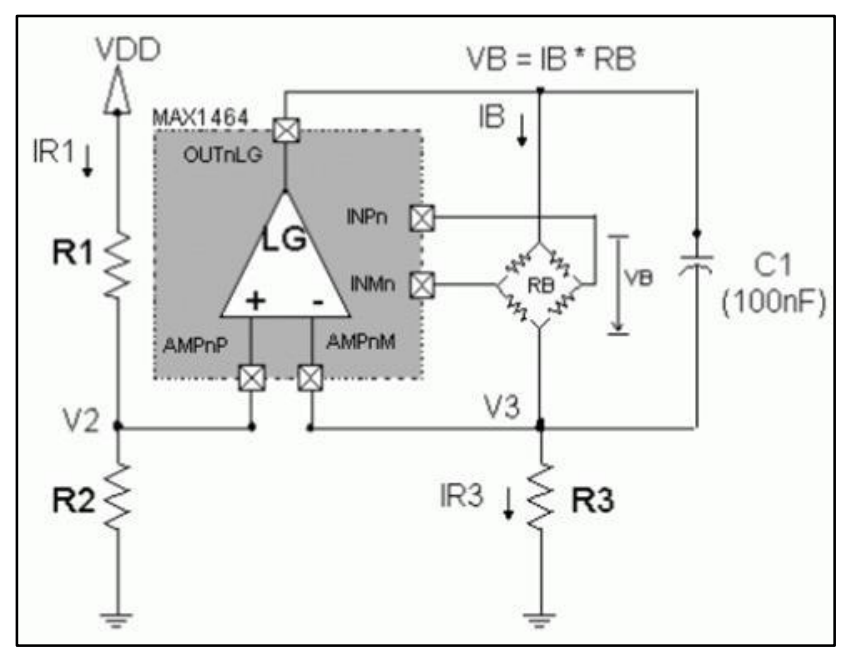

Figura 18 - Fonte de corrente do sensor de pressão (Luz, 2008).

Com o objetivo de calibrar o sensor de pressão diferencial em uma faixa menor que o limite máximo dele, foi necessário modificar a fonte de corrente de excitação do sensor. Para isto projetou-se uma nova corrente de $I_{\text {exc }}=500 \mathrm{uA}$ alterando os valores dos resistores $R_{1}=150 \mathrm{k} \Omega$ e $R_{2}=330 \mathrm{k} \Omega$. Com essa nova corrente de excitação foi possível reduzir a faixa de pressão diferencial do sensor de $P_{d 1}=35$ bard até 0 valor de $P_{d 2}=25$ bard. Para essa faixa de pressão calibrada foi obtida uma tensão de saída de $V_{\text {out }}=40,8 \mathrm{mV}$, isto se mostra na Tabela 3 e Figura 19. Essa tensão de saída cumpre com as condições de faixa de sensibilidade de entrada do DSSP MAX1464 ((Integrated (2004)) e também satisfaz os requisitos de consumo mínimo de corrente do circuito eletrônico do transmissor de pressão (Luz (2008)). 
Tabela 3: Variação do SPAN do sensor de pressão para diferentes correntes de excitação.

\begin{tabular}{|c|c|c|c|}
\hline \multicolumn{4}{|c|}{ Sensor Diferencial Piezoresistivo MDM290 } \\
\hline $\begin{array}{c}\text { Pressão } \\
\text { Diferencial [bard] }]\end{array}$ & I=230 uA & I=400 uA & I=500 uA \\
\cline { 2 - 4 } & Vout[mV] & Vout[mV] & Vout[mV] \\
\hline 0 & $-1,89$ & $-3,288$ & $-4,133$ \\
\hline 2,5 & 0,158 & 0,279 & 0,372 \\
\hline 5 & 2,223 & 3,903 & 4,872 \\
\hline 7,5 & 4,283 & 7,457 & 9,353 \\
\hline 10 & 6,343 & 11,053 & 13,802 \\
\hline 12,5 & 8,393 & 14,639 & 18,341 \\
\hline 15 & 10,493 & 18,219 & 22,841 \\
\hline 17,5 & 12,515 & 21,786 & 27,325 \\
\hline 20 & 14,556 & 25,393 & 31,805 \\
\hline 22,5 & 16,642 & 28,94 & 36,296 \\
\hline 25 & 18,65 & 32,544 & 40,821 \\
\hline 27,5 & 20,296 & 36,118 & 45,259 \\
\hline 30 & 22,795 & 39,682 & 49,741 \\
\hline 32,5 & 24,83 & 43,286 & 54,223 \\
\hline 35 & 26,916 & 46,826 & 58,69 \\
\hline \multicolumn{3}{|c}{} \\
\hline
\end{tabular}

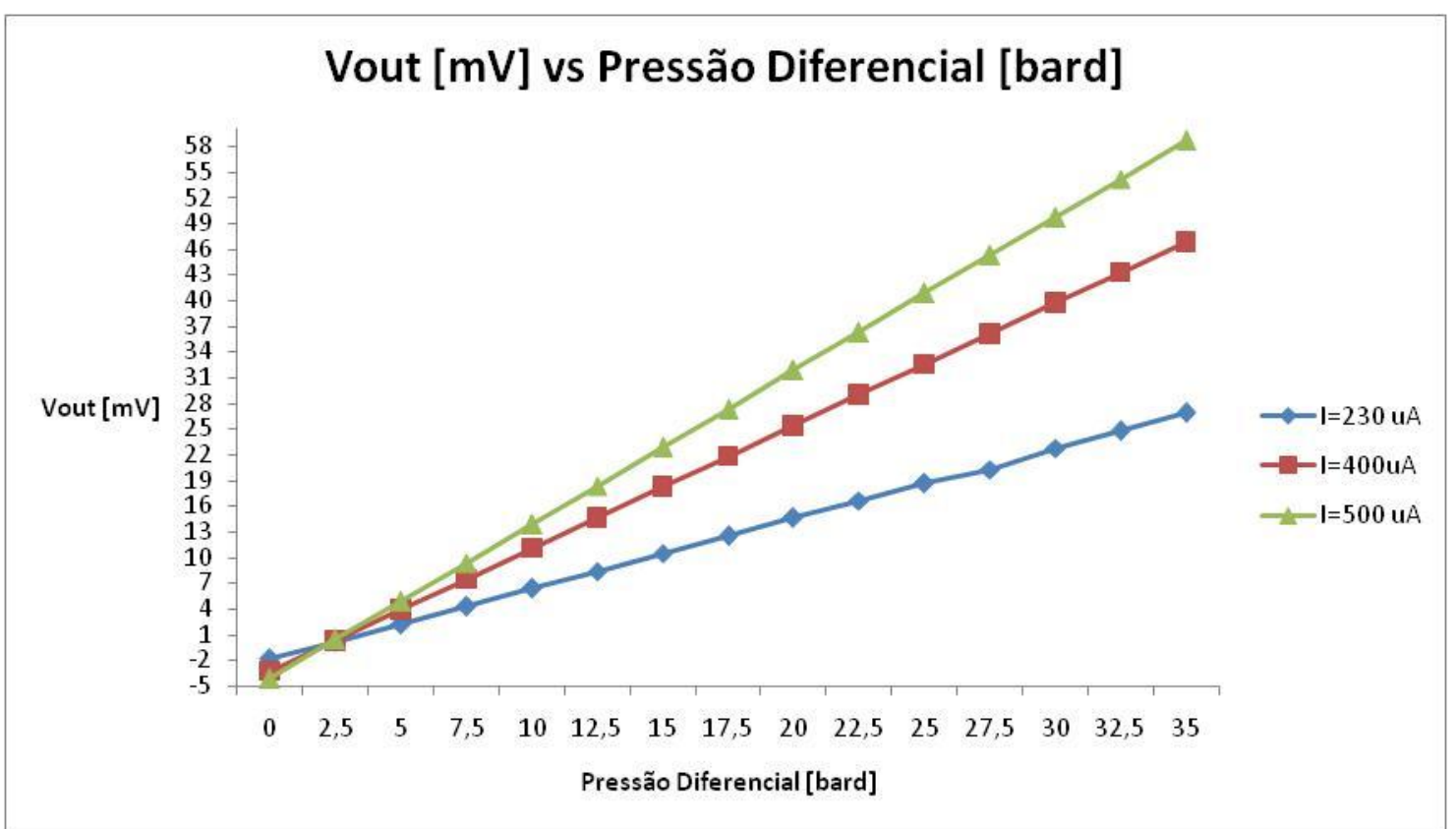

Figura 19-Sensibilidade do sensor de pressão em relação a diferentes correntes de excitação. 


\subsubsection{Projeto do Conversor Tensão-Corrente}

No conversor tensão-corrente também se usa um amplificador operacional dos internos do MAX1464. Na escolha do transistor se considerou a potência máxima que este pode suportar, na máxima temperatura de operação do transmissor. Selecionou-se o transistor 2N3440. Para o cálculo dos resistores que fixam os parâmetros de trabalho do conversor tensão-corrente foram usadas as equações da nota de aplicação da MAXIM. (Beltrán (2005)), (Integrated (2002)). Na Figura 20 se apresenta o esquema do circuito tensão-corrente projetado.

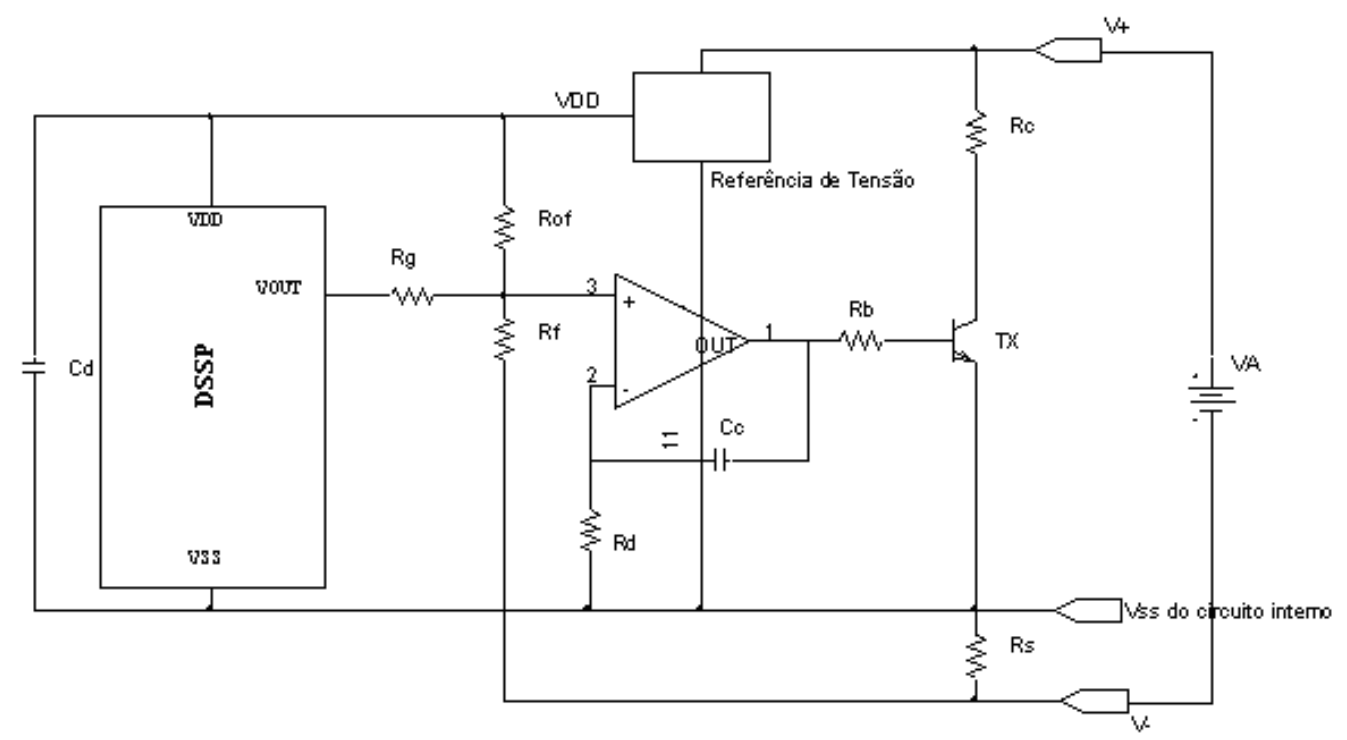

Figura 20 - Esquema do circuito tensão-corrente (Beltrán, 2005).

\subsubsection{Fonte de Tensão do Circuito Eletrônico}

$\mathrm{Na}$ escolha da referência de tensão para implementar a fonte de alimentação de todo o circuito teve que se considerar o consumo de corrente do DSSP no momento da gravação do firmware. Este valor pode chegar até $30 \mathrm{~mA}$ e deve ser garantido pela referência. Outro aspecto a ser considerado é que a tensão máxima na entrada da 
referência fosse compatível com a máxima tensão de trabalho do transmissor, conseguindo desta forma não ter que colocar componentes adicionais para reduzir a tensão na entrada da referência (Beltrán (2005)). Foi selecionada para o projeto a referência MAX15006B da MAXIM que fornece uma tensão de saída de $5 \mathrm{~V}$ e entradas na faixa de 4V até 40V (Integrated (2012)). As características de tensão deste regulador são compatíveis com as necessidades de consumo e alimentação dos componentes da placa eletrônica usada no projeto. No Anexo A e a Figura 21 se apresentam respectivamente o esquemático e o circuito eletrônico desenvolvido para realizar 0 condicionamento e processamento do sinal do sensor de pressão diferencial.

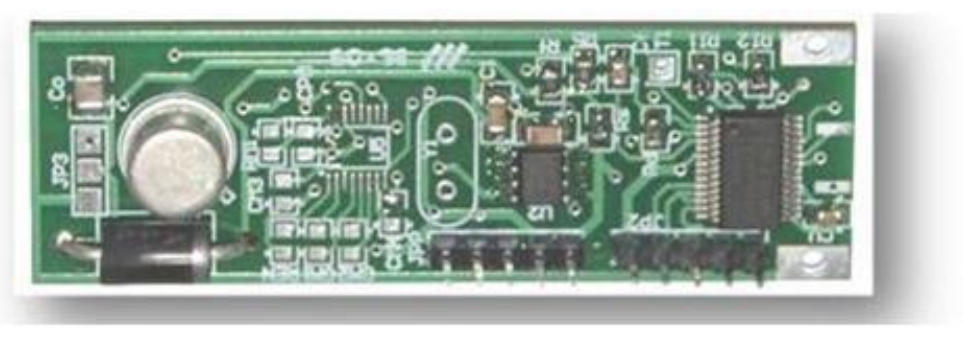

Figura 21 - Circuito eletrônico do transmissor de pressão diferencial.

\subsection{Calibração e Compensação: Fundamentos}

A maioria dos sensores precisa de correção das características não desejadas como a não linearidade e a dependência da sensibilidade com a temperatura. No caso específico dos sensores de pressão piezoresistivos estes apresentam, fundamentalmente não linearidade, uma saída diferente de zero quando não tem pressão aplicada (offset), dependência térmica tanto do span quanto do offset e a necessidade de calibrar sua saída para uma faixa determinada devido às variações do processo de fabricação dos sensores.

Neste trabalho foram utilizados dois algoritmos desenvolvidos pela MAXIM. Um deles para calibrar e caracterizar os transmissores de pressão e outro para fazer a compensação do sensor utilizando a tecnologia DSSP. O processo de correção das 
características do sensor divide-se em dois passos fundamentais: Um deles é executado in factory, ou seja, durante a fabricação do transmissor e consiste em obter numa bancada de calibração os coeficientes específicos que corrigem as características do sensor e do circuito de condicionamento do sinal. Para isto é utilizado um algoritmo de calibração que obtém os coeficientes específicos para cada transmissor. O segundo passo é executado in service, ou seja, quando o transmissor esta medindo a pressão e consiste em executar em tempo real as equações de correção dos dados medidos pelo sensor e fornecer à saída o resultado da medição compensado. Para isto é utilizado um algoritmo de compensação que tem como base a utilização de polinômios de segunda ordem. As correções ao sinal do sensor são feitas no domínio digital e posteriormente se faz a correção do bloco de saída analógica do transmissor. Este algoritmo foi implementado para o chip MAX1464 em específico. As funções de correção são implementadas na CPU do MAX1464 sendo que o que muda de um transmissor para outro são os coeficientes destas funções que foram calculados in factory ((Herrera, 2013)), (Ltda (2008)), (Charry (2007)).

\subsubsection{Algoritmo de Calibração dos Transmissores de Pressão}

Para obter os valores dos coeficientes das funções de correção, os transmissores são avaliados para determinar as variações do sensor e dos diferentes blocos do circuito de acondicionamento que podem afetar a saída analógica dos transmissores. Para isto utiliza-se um sistema de calibração constituído por uma câmara climática com controle de temperatura e umidade, dois calibradores de pressão, um multímetro de alta precisão, uma fonte de alimentação e um computador. O sistema está totalmente automatizado e permite calibrar de forma paralela até 16 transmissores de pressão (Integrated (2005a)); (Herrera, 2013). Na Figura 22 verificamos uma representação do sistema de calibração. 


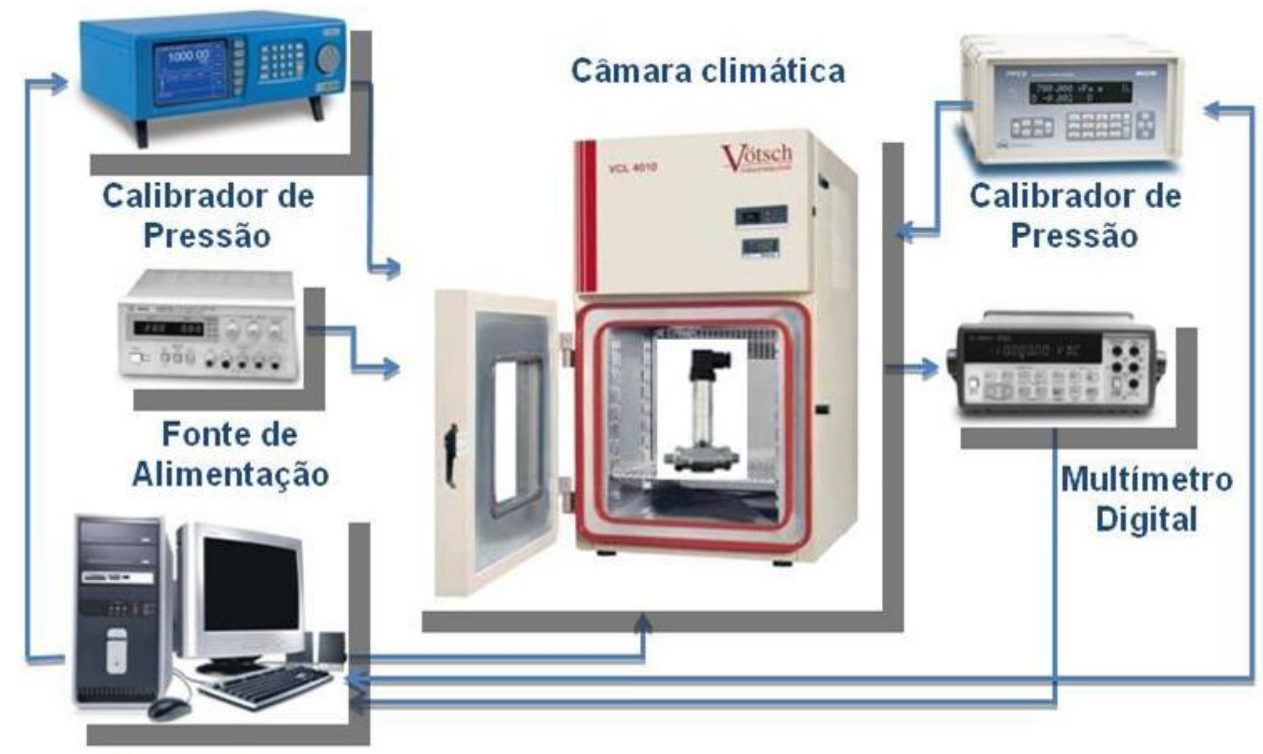

Computador

Figura 22 - Sistema de calibração dos transmissores de pressão.

Mediante o procedimento matemático descrito no item 3.4.2 se obtêm os coeficientes e estes são gravados como constantes no programa base que se executa na CPU do MAX1464 de cada transmissor. O diagrama de blocos do algoritmo de calibração é apresentado na Figura 23. Neste algoritmo, a partir de uma matriz de dados obtida experimentalmente, modelam-se matematicamente os dados do sensor de pressão, do sensor de temperatura do MAX1464 e do bloco de saída analógica. Posteriormente se modela a correção dos dados de temperatura e com a função que representa a temperatura já corrigida é que se faz a modelagem da correção dos dados de pressão e do bloco analógico de saída (ver diagrama do transmissor na Figura 14).

Partindo destas modelagens feitas é possível obter os coeficientes necessários para fazer a compensação de cada bloco do transmissor: pressão, temperatura do MAX1464 e saída analógica. 


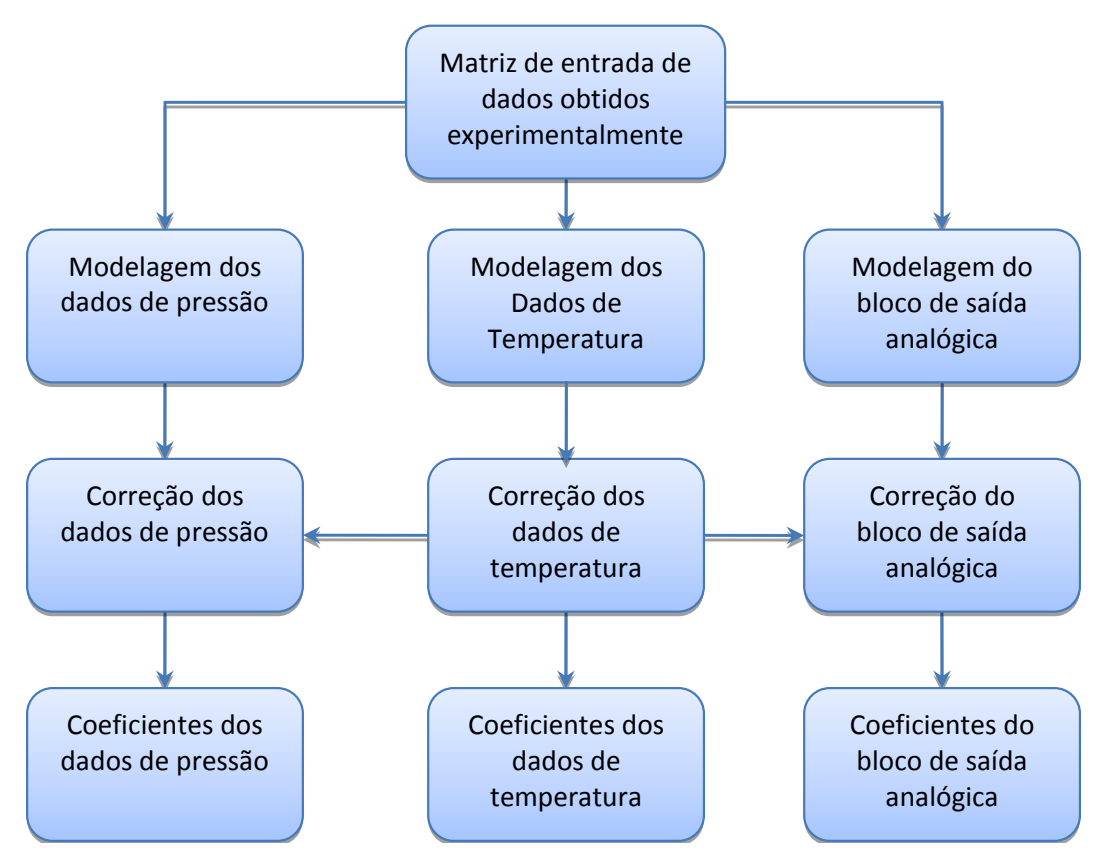

Figura 23 - Diagrama em blocos do algoritmo de calibração dos transmissores.

Para modelar o comportamento do sensor de pressão utilizam-se nove pontos obtidos experimentalmente medindo o sinal da saída para três pressões diferentes (Pmin, Pmed e Pmax) a cada uma das três temperaturas de referência (Tmin, Tmed e Tmax). Desta forma é obtida por interpolação uma função que depende da pressão e da temperatura composta por nove pontos de interpolação. Esta função representa o comportamento do sensor de pressão.

Num primeiro passo obtêm-se os dados de pressão para cada temperatura independente para assim obter as funções que caracterizam esses dados a cada temperatura. Posteriormente com estas três funções obtidas para as três temperaturas será modelado como variam os coeficientes das funções com a temperatura para assim obter uma função única que represente o comportamento dos dados de pressão com a temperatura e a pressão. Como em ambos os casos a interpolação realiza-se com três pontos, as funções obtidas são de segunda ordem e como a função geral obtida depende de duas variáveis, esta representará uma superfície no espaço.

O objetivo da modelagem dos dados de temperatura é obter uma função que represente o comportamento do sensor de temperatura partindo de três dados obtidos 
na saída do conversor ADC quando este mede o sensor de temperatura. Com esses três pontos medidos se obtêm uma função de segundo grau que passe por eles usando interpolação. Isto significa uma aproximação, pois a partir de apenas três pontos se está estimando o comportamento do sensor de temperatura em toda a faixa.

O bloco de saída analógico composto pelo conversor digital-analógico (DAC) e o conversor tensão-corrente (V-I) também deve ser modelado para conhecer seu comportamento com a temperatura. No algoritmo ele é modelado como uma reta onde os parâmetros da mesma têm dependência térmica. Desta forma considera-se que os erros de linearidade que pode introduzir este bloco não precisam ser corrigidos. Para modelar este bloco se obtêm os valores de corrente na sua saída para dois valores de referência diferentes colocados na entrada do DAC às três temperaturas Tmin, Tmed e Tmax.

O objetivo principal deste processo de calibração é determinar os coeficientes independentes que caracterizam e compensam cada transmissor individualmente. A utilização destes coeficientes no MAX1464 torna possível obter na saída do transmissor a corrente de $4 \mathrm{~mA}$ quando é aplicada a pressão mínima no sensor, assim como obter $20 \mathrm{~mA}$ na saída para a pressão máxima, independentemente da temperatura. Então, é possível calibrar um sensor numa faixa de pressão menor que a máxima, já que o processo de calibração permite obter os coeficientes para ajustar a corrente de saída entre 4 e 20mA para a faixa de pressão desejada. Em Herrera (2013) se apresentam os passos que devem ser seguidos no processo de calibração dos transmissores de pressão. 


\subsubsection{Algoritmo de Compensação Implementado nos Transmissores de Pressão}

$\mathrm{Na}$ literatura têm sido reportados vários algoritmos para fazer o condicionamento do sinal de sensores (Philip C. et al. (2010)), (Chuan e Chen (2010)). A seleção de um algoritmo em particular depende das características do sinal de saída do sensor e da capacidade do dispositivo inteligente que é utilizado no desenvolvimento.

É importante compreender a forma com a qual se corrigem os erros do sinal de cada um dos blocos que fazem parte do transmissor de pressão. Como se pode ver na Figura 24, a CPU (central processing unit) se encontra depois dos sensores de pressão e temperatura, mas antes do bloco analógico de saída. Visto que a correção em tempo real acontece na CPU, se nesta se corrigem somente os erros do sensor de pressão e de temperatura, quando o sinal é enviado ao bloco analógico de saída, este degrada a correção realizada por ser ele também sensível à temperatura. Para que isto não aconteça deve-se caracterizar também o bloco analógico de saída para saber como afetaria o sinal. Então a CPU, antes de enviar o dado ao DAC, deve modifica-lo na mesma magnitude, mas em sentido contrário a como seria afetado pelo bloco para obter na saída do mesmo o valor desejado. Ou seja, os erros do sinal de pressão e temperatura são corrigidos depois que acontecem e os erros do DAC são corrigidos antes (Arturo Hernández González (2009)).

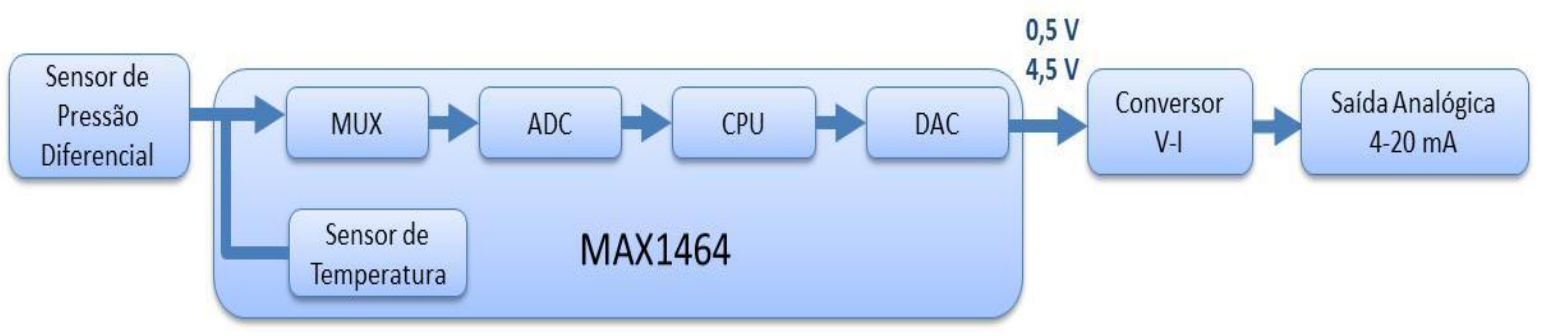

Figura 24 - Diagrama de blocos do DSSP MAX1464. 
No desenvolvimento deste trabalho foi utilizado um algoritmo baseado em uma compensação polinomial de segundo grau. Quando o transmissor se encontra em funcionamento, o DSSP obtém os valores de pressão $(P)$ e temperatura $(T)$ do circuito eletrônico e executa uma compensação polinomial para obter o valor de pressão compensada PC dado pela eq.(11).

$$
\mathbf{P C}(\mathbf{P}, \mathbf{T})=\mathbf{X}(\mathbf{T})+\mathbf{Y}(\mathbf{T}) * \mathbf{P}+\mathbf{Z}(\mathbf{T}) * \mathbf{P}^{2}
$$

Os coeficientes $X, Y$ e $Z$ são dependentes da temperatura e têm que ser obtidos através das seguintes equações: eq.(12), eq.(13) e eq.(14).

$$
\begin{aligned}
& \mathbf{X}(\mathbf{T})=\mathbf{X}_{0}+\mathbf{X}_{1} * \mathbf{T}+\mathbf{X}_{2} * \mathbf{T}^{2} \\
& \mathbf{Y}(\mathbf{T})=\mathbf{Y}_{0}+\mathbf{Y}_{1} * \mathbf{T}+\mathbf{Y}_{2} * \mathbf{T}^{2} \\
& \mathbf{Z}(\mathbf{T})=\mathbf{Z}_{\mathbf{0}}+\mathbf{Z}_{1} * \mathbf{T}+\mathbf{Z}_{\mathbf{2}} * \mathbf{T}^{\mathbf{2}}
\end{aligned}
$$

Os coeficientes $X_{0}, X_{1}, X_{2}, Y_{0}, Y_{1}, Y_{2}, Z_{0}, Z_{1}$ e $Z_{2}$ devem ser calculados $\mathrm{e}$ gravados previamente na memória de programa do DSSP durante o processo de calibração do transmissor.

Para obter uma saída analógica compensada (SA) deve-se realizar a compensação térmica do bloco analógico de saída (DAC e conversor V-I). O valor da saída analógica pode ser calculado utilizando a. eq.(15)

$$
\mathbf{S A}(\mathbf{P}, \mathbf{T})=\mathbf{W}(\mathbf{T}) * \mathbf{P C}(\mathbf{P}, \mathbf{T})+\mathbf{K}(\mathbf{T})
$$

Os coeficientes $\mathrm{W}$ e $\mathrm{K}$ dependem da temperatura e podem ser obtidos utilizando as equações: eq.(16) e eq.(17).

$$
\begin{aligned}
& \mathbf{W}(\mathbf{T})=\mathbf{W}_{\mathbf{0}}+\mathbf{W}_{\mathbf{1}} * \mathbf{T}+\mathbf{W}_{\mathbf{2}} * \mathbf{T}^{2} \\
& \mathbf{K}(\mathbf{T})=\mathbf{K}_{\mathbf{0}}+\mathbf{K}_{\mathbf{1}} * \mathbf{T}+\mathbf{K}_{\mathbf{2}} * \mathbf{T}^{2}
\end{aligned}
$$


Os coeficientes $\mathrm{W}_{0}, \mathrm{~W}_{1}, \mathrm{~W}_{2}, \mathrm{~K}_{0}, \mathrm{~K}_{1}$ e $\mathrm{K}_{2}$ também devem ser calculados no processo de calibração do transmissor de pressão.

Então, utilizando o algoritmo descrito acima o MAX1464 faz in service a correção da não linearidade, do offset e do ganho do sinal do sensor de pressão e a dependência térmica das características do sensor. 


\section{CARACTERIZAÇÃO DOS PARÂMETROS DE SAÍDA DO SENSOR E DO TRANSMISSOR DE PRESSÃO DIFERENCIAL: TESTES E RESULTADOS}

Nesta seção é feita a caracterização e a comparação do erro das saídas dos sensores e transmissores de pressão diferencial. Assim mesmo é mostrada a estabilidade e confiabilidade da saída do transmissor a curto e longo prazos usando a norma BS 6174:1982.

Para realizar a caracterização dos sensores e dos transmissores de pressão diferencial foi usada a metodologia das normas BS 61298-2:2008 e BS 60770-2:2011. Por meio desta caracterização foi calculado o TEB o qual se compõe dos parâmetros da não linearidade, histerese, repetibilidade, coeficiente térmico do Zero (TCO) e coeficiente térmico do Span (TCS).

$\mathrm{Na}$ metodologia recomenda-se para a avaliação do desempenho dos dispositivos realizar entre 3 e 5 ciclos de pressão em toda a faixa de operação para valores crescentes e decrescentes.. A quantidade e a localização dos pontos de teste devem ser consideradas dependendo do tipo de teste desejado, do grau de exatidão desejada e das características avaliadas (Cenelec (2008)), (Cenelec (2011)). Na tabela 4 são mostradas a quantidade de ciclos de medição e a quantidade e localização dos pontos de teste recomendados, dependendo das necessidades.

Tabela 4 - Total de Ciclos de Medição. Quantidade e Localização dos Pontos de Teste (Cenelec, 2008)

\begin{tabular}{lccl}
\hline Tipo de teste & $\begin{array}{l}\text { Quantidade de } \\
\text { ciclos de } \\
\text { mediçăo }\end{array}$ & $\begin{array}{l}\text { Quantidade de } \\
\text { pontos de teste }\end{array}$ & $\begin{array}{l}\text { Localizaçăo dos pontos de teste } \\
\text { (\% do span de entrada) }\end{array}$ \\
\hline $\begin{array}{l}\text { Avaliação de desempenho } \\
\text { Testes de caracterização }\end{array}$ & 3 ou 5 & 6 & $\begin{array}{l}0-20-40-60-80-100 \\
0-10-20-30-40-50-60-70-80-90-100\end{array}$ \\
$\begin{array}{l}\text { Teste de rotina } \\
\text { Teste de exemplo }\end{array}$ & 1 & 11 & $0-25-50-75-100$ \\
\hline
\end{tabular}


Para os objetivos do projeto selecionou-se fazer três ciclos de pressão. Cada ciclo compreendeu uma rampa positiva e uma rampa negativa de pressão, sendo que os valores de pressão foram variados em passos de $20 \%$ desde 0 até o valor máximo de pressão, ou seja, 6 pontos de medição na caracterização dos sensores de pressão. No caso dos transmissores de pressão foram tomados cinco pontos na faixa total de pressão com passos de $25 \%$.

Com estes dados foi gerada uma tabela para cada ponto de teste em cada um dos ciclos colocando os erros de saída. Estes erros são a diferença entre o valor da saída e o valor ideal, definidos como porcentagem da amplitude do sinal de saída (\%FSO). Adicionalmente é colocada nesta tabela a media dos erros das rampas positivas dos três ciclos, da rampa negativa e uma media geral obtida a partir da media da rampa positivas e da rampa negativa para cada ponto de teste.

A partir dos dados de erros da tabela são calculados os parâmetros de repetibilidade, histerese e não linearidade tanto nos sensores como nos transmissores de pressão (Cenelec, 2008), (Cenelec, 2011). A seguir são definidos os parâmetros de Exatidão, TCO, TCS e TEB.

\subsection{Exatidão}

A exatidão é dada como a raiz quadrada da soma dos quadrados da repetibilidade, histerese e repetibilidade (Instrumentation,2008). As unidades da exatidão são expressas em função da porcentagem de escala plena [\%FSO] como se mostra na eq.(18).

Exatidão $[\%$ FSO $]=\sqrt{\text { NãoLinearidade }{ }^{2}+\text { Repetibilidade }^{2}+\text { Histerese }^{2}}$ 


\subsection{Coeficiente de Temperatura do Offset (TCO)}

O offset é a saída do sensor à temperatura de referência (Tref) quando a pressão aplicada é zero, ou seja, é o desvio de zero do sinal de saída quando a entrada é zero (pressão). O offset varia com a temperatura. O coeficiente de temperatura do Offset é definido como o desvio máximo na saída quando a temperatura varia desde a temperatura de referência (Tref) até qualquer outra temperatura (T) na faixa de operação do sensor. É especificado como $\% \mathrm{FSO} /{ }^{\circ} \mathrm{C}$. O calculo do valor do TCO é estabelecido pela relação da eq.(19).

$$
\text { TCO }[\% \text { FSO }]=\left(\frac{\text { offset }(\mathrm{T})-\text { offset }\left(\mathrm{T}_{0}\right)}{\mathrm{T}-\mathrm{T}_{0}}\right),
$$

onde "Offset $\left(\mathrm{T}_{0}\right)$ " é o offset à temperatura de referência, "T" é a temperatura, " $\mathrm{T}_{0}$ " é a temperatura de referência e "TCO" é o coeficiente de temperatura do offset.

\subsection{Coeficiente de Temperatura do Span (TCS)}

O coeficiente de temperatura do Span é definido como o desvio máximo do span quando a temperatura varia desde a temperatura de referência (Tref) até qualquer outra temperatura $(\mathrm{T})$ na faixa de operação do sensor, e é especificado como \% FSO $/{ }^{\circ} \mathrm{C}$. $\mathrm{O}$ valor do TCS é estabelecido pela relação da eq.(20).

$$
\mathbf{T C S}[\% \mathbf{F S O}]=\left(\frac{\operatorname{Span}(\mathbf{T})-\operatorname{Span}\left(\mathbf{T}_{0}\right)}{\mathbf{T}-\mathbf{T}_{0}}\right)
$$

Onde "Span $\left(\mathrm{T}_{0}\right)$ " é o span à temperatura de referência, "T" é a temperatura, " $\mathrm{T}_{0}$ " é a temperatura de referência e "TCS" é o coeficiente de temperatura do span. 


\subsection{Total Error Band - TEB}

O Total Error Band (TEB) é definido como o máximo desvio da saída com respeito à função de transferência ideal do dispositivo nas faixas inteiras de pressão e temperatura. Na Figura 25 pode-se ver que o TEB inclui todos os erros devido ao offset, span de escala plena, não linearidade de pressão, histerese de pressão, não repetibilidade, coeficiente térmico do offset, coeficiente térmico do SPAN e histerese térmica (Honeywell, 2011). Por meio da eq.(21) pode-se expressar de forma aproximada o valor do TEB.

$$
\text { TEB }(\% \text { FSO }) \approx \sqrt{\left(\text { Exatidão }^{2}\right)+\left(\mathbf{T C S}^{2}\right)+\left(\mathbf{T C O}^{2}\right)}
$$

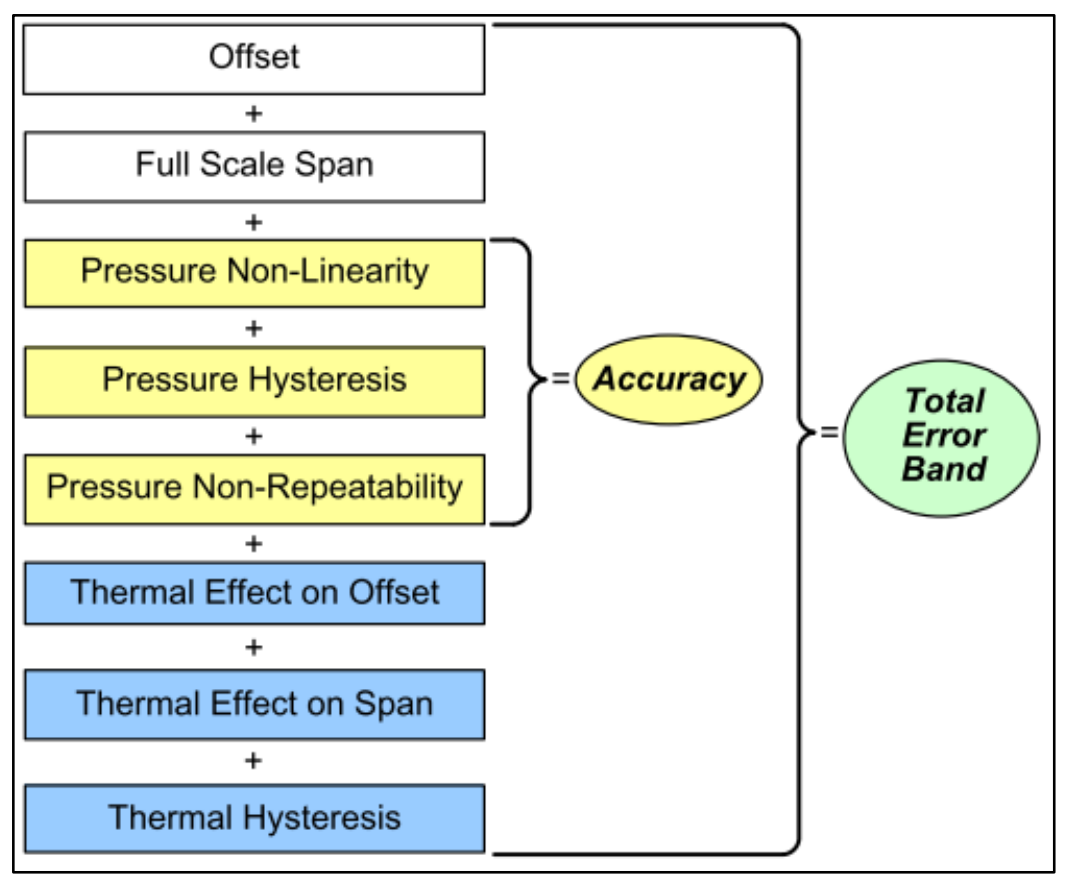

Figura 25: Soma de todos os possíveis erros usados no cálculo do TEB. (Honeywell, 2011). 


\subsection{Caracterização dos Sensores Diferenciais sem Compensar e sem Calibrar}

Neste processo de caracterização foram usados dez sensores de pressão diferencial MDM290 da empresa Microsensor, calibrados na faixa de pressões diferenciais de 0 até 25 bard e de pressão de linha de 7 barg.

As temperaturas de teste foram $0^{\circ} \mathrm{C}, 20^{\circ} \mathrm{C}, 40^{\circ} \mathrm{C}, 55^{\circ} \mathrm{C}$ e $70^{\circ} \mathrm{C}$ com tempos de estabilização de 90 minutos (Charry, 2007). Realizaram-se três ciclos de medição de pressão com seis pontos de teste ao 0, 20, 40,60, 80 e 100\% da amplitude da faixa nominal de pressão diferencial.

\subsubsection{Equipamentos}

Os três ciclos de pressão diferencial foram controlados por dois calibradores de pressão: o calibrador DRUCK DPI 515 e o calibrador PPC3 da Fluke.

O controle de temperatura e umidade foi feito por meio da câmera climática Votch VCL 40003.

O sistema de excitação dos sensores esteve conformado de uma fonte de tensão Agilent E3640A em série com uma fonte de corrente KEITHLEY 2400. A corrente de excitação dos sensores foi de $1,5 \mathrm{~mA}$ DC (valor recomendado pela folha de dados do fabricante dos sensores)..

A medição das tensões de saída de cada um dos sensores foi realizada por meio de dez multímetros digitais Agilent34401 com exatidão de $0,1 \%$ da leitura.

Todos os equipamentos têm comunicação RS232-USB com um PC o qual usa uma interface de usuário feita em Labview para o controle de cada um dos equipamentos e a 
leitura dos dados de saída dos sensores. Na Figura 26 é apresentado o sistema de instrumentação usado na caracterização dos sensores diferenciais.

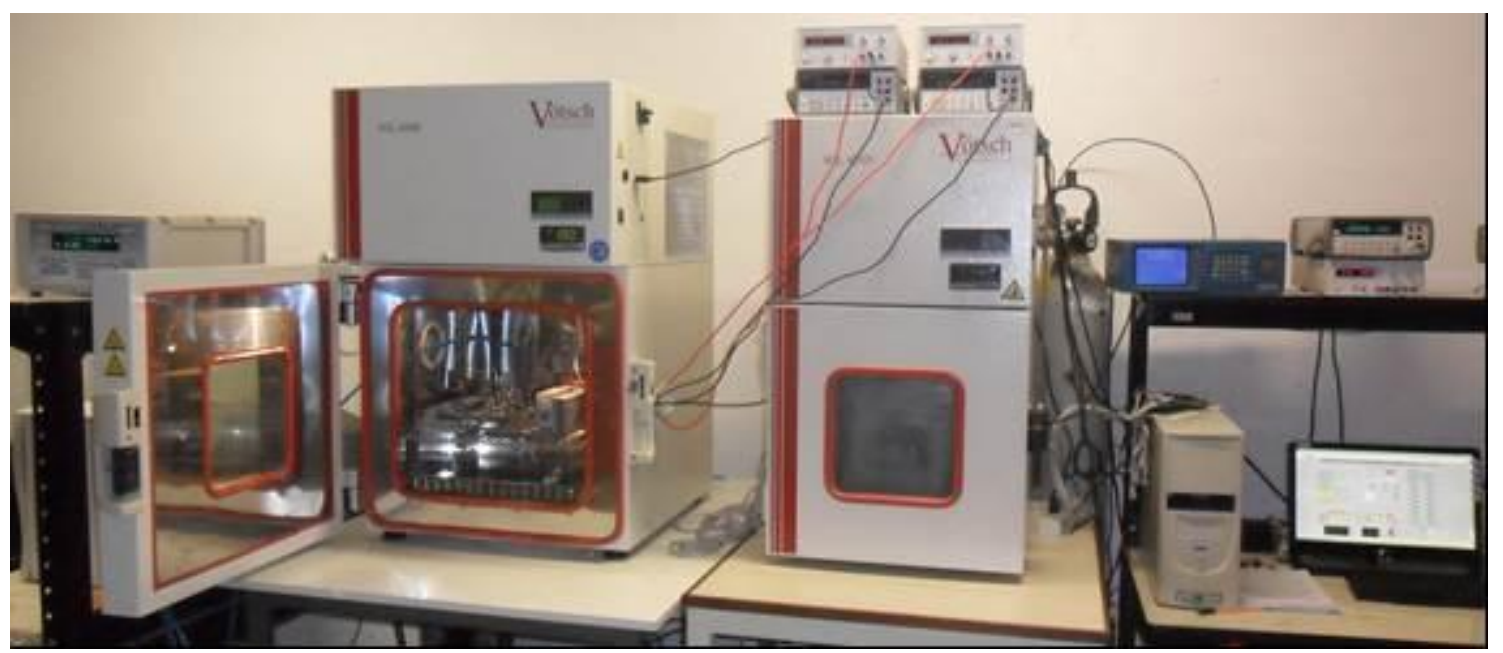

Figura 26 - Equipamentos usados na caracterização dos sensores e transmissores de pressão diferencial.

\subsubsection{Medições}

Na Tabela 5 estão listados os dados de saída de um sensor de pressão para os três ciclos de pressão na temperatura de $20^{\circ} \mathrm{C}$. Com base nestes dados é calculado o valor de exatidão do sensor que será apresentado na seção de resultados.

Tabela 5 - Tensão de saída para um sensor diferencial durante 3 ciclos de pressão

\begin{tabular}{|c|c|c|c|c|c|c|}
\hline \multicolumn{7}{|c|}{ Temperatura: $20^{\circ} \mathrm{C}$} \\
\hline & \multicolumn{2}{|c|}{ Ciclo 1} & \multicolumn{2}{|c|}{ Ciclo 2} & \multicolumn{2}{|c|}{ Ciclo 3} \\
\hline $\begin{array}{c}\text { \% SPAN de } \\
\text { Entrada }\end{array}$ & $\begin{array}{c}\text { Rampa de } \\
\text { Subida [mV] }\end{array}$ & $\begin{array}{c}\text { Rampa de } \\
\text { Descida [mV] }\end{array}$ & $\begin{array}{c}\text { Rampa de } \\
\text { Subida [mV] }\end{array}$ & $\begin{array}{c}\text { Rampa de } \\
\text { Descida [mV] }\end{array}$ & $\begin{array}{l}\text { Rampa de } \\
\text { Subida [mV] }\end{array}$ & $\begin{array}{c}\text { Rampa de } \\
\text { Descida [mV] }\end{array}$ \\
\hline 0 & $-8,59568$ & $-8,60356$ & $-8,61278$ & $-8,61686$ & $-8,57974$ & $-8,62452$ \\
\hline 20 & 19,66924 & 19,707 & 19,70526 & 19,72362 & 19,70402 & 19,77588 \\
\hline 40 & 47,91874 & 47,98878 & 48,05008 & 48,03876 & 48,04244 & 48,20158 \\
\hline 60 & 76,15606 & 76,26576 & 76,46018 & 76,2627 & 76,33948 & 76,52368 \\
\hline 80 & 104,47254 & 104,58888 & 104,66334 & 104,59626 & 104,63768 & 104,80018 \\
\hline 100 & 132,7154 & 132,68224 & 132,92974 & 132,99906 & 132,95894 & 133,0409 \\
\hline
\end{tabular}


Na Tabela 6 e Figura 27 pode-se ver o comportamento da saída média em tensão de um dos sensores de pressão na faixa de temperaturas de $0^{\circ} \mathrm{C}$ até $70^{\circ} \mathrm{C}$. Observa-se que existem deslocamentos do offset e do SPAN com relação à temperatura, estes desvios na saída de tensão dos sensores serão corrigidos pelo sistema de compensação e calibração do transmissor de pressão.

Tabela 6 - Tensões de saída de um sensor de pressão na faixa de temperaturas de $0^{\circ} \mathrm{C}$ até $70^{\circ} \mathrm{C}$

\begin{tabular}{cccccc}
\hline Temperatura $\left[{ }^{\circ} \mathrm{C}\right]$ & $0^{\circ} \mathrm{C}$ & $20^{\circ} \mathrm{C}$ & $40^{\circ} \mathrm{C}$ & $55^{\circ} \mathrm{C}$ & $70^{\circ} \mathrm{C}$ \\
\hline $\begin{array}{c}\text { \% SPAN de } \\
\text { entrada }\end{array}$ & $\begin{array}{c}\text { Saída do } \\
\text { sensor [mV] }\end{array}$ & $\begin{array}{c}\text { Saída do } \\
\text { sensor [mV] }\end{array}$ & $\begin{array}{c}\text { Saída do } \\
\text { sensor [mV] }\end{array}$ & $\begin{array}{c}\text { Saída do } \\
\text { sensor [mV] }\end{array}$ & $\begin{array}{c}\text { Saída do } \\
\text { sensor [mV] }\end{array}$ \\
\hline 0 & 0,34803 & $-8,60627$ & $-9,12513$ & $-9,66852$ & $-8,38997$ \\
20 & 28,24889 & 19,71382 & 19,5135 & 18,89397 & 19,42397 \\
40 & 56,10665 & 48,0406 & 48,1131 & 47,24068 & 48,12906 \\
60 & 83,95341 & 76,30262 & 76,7155 & 75,68066 & 76,5475 \\
80 & 111,76219 & 104,61697 & 105,22661 & 103,81621 & 105,01811 \\
100 & 139,43476 & 132,9644 & 133,35123 & 132,24043 & 133,585 \\
\hline
\end{tabular}

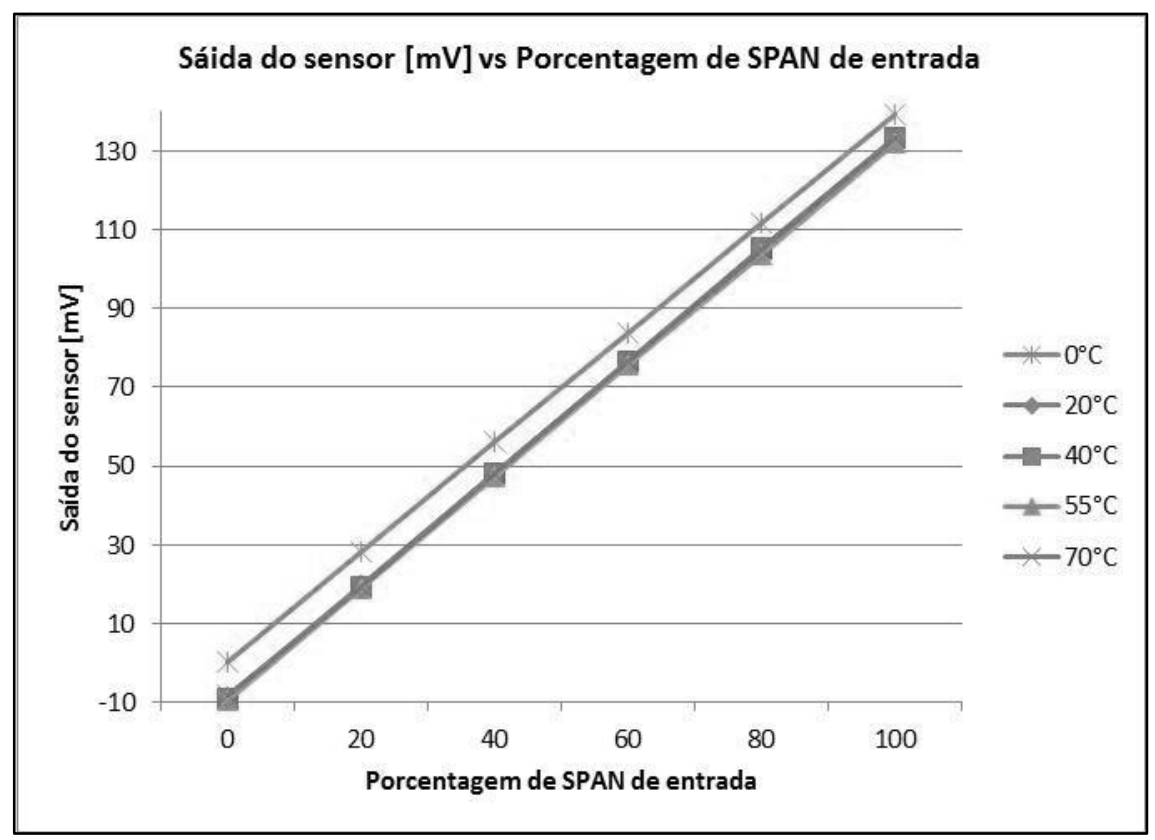

Figura 27 - Saída do sensor vs porcentagem de entrada 
Na Figura 28 se demonstra a variação do erro médio do sensor com respeito à pressão diferencial e à temperatura, os maiores valores de erro se encontram na faixa de baixas pressões de 0 até 2,5 bard e nas temperaturas de 55 até $70^{\circ} \mathrm{C}$. Estes dados mostram que o erro do sensor de pressão tem dependência térmica.

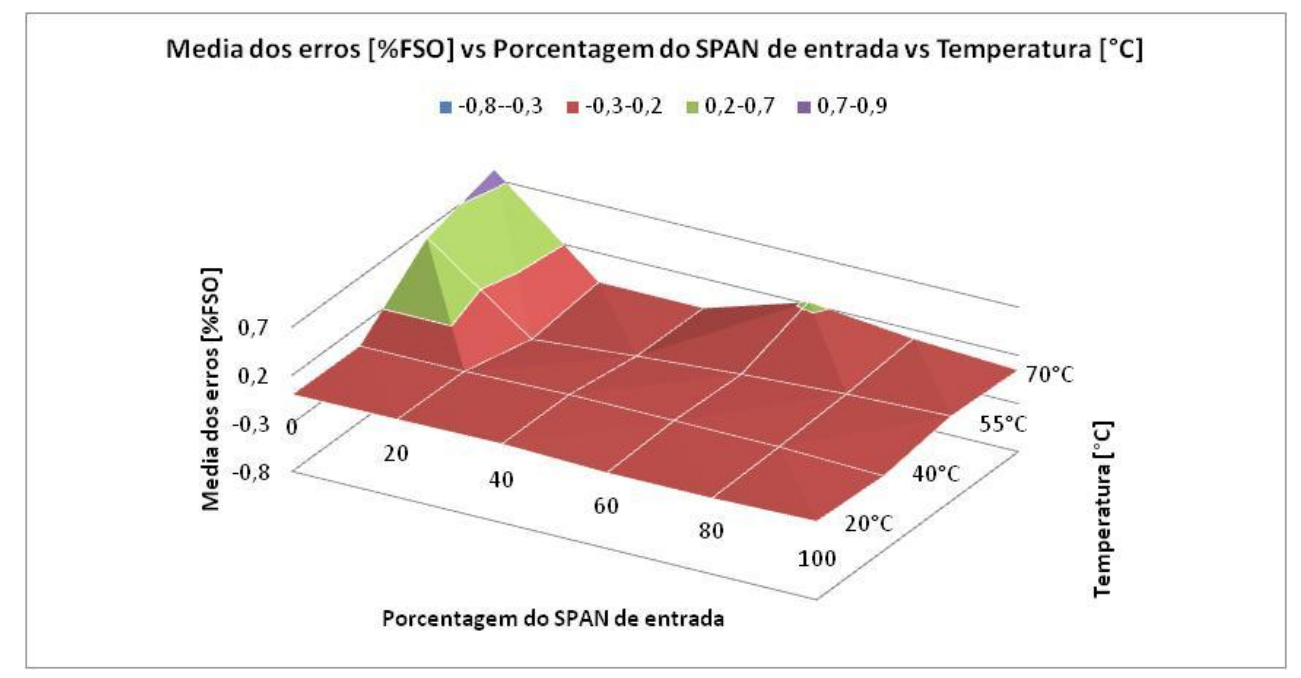

Figura 28 - Variação do erro [\%FSO] vs Pressão diferencial [bar] vs Temperatura ${ }^{\circ} \mathrm{C}$ ]

\subsubsection{Resultados}

Na Tabela 7 são listados os valores máximos de repetibilidade, histerese e não linearidade. Usando a equação 18 foi obtida uma Exatidão=0,2140 [\%FSO] a qual é menor que o valor especificado na folha de dados do sensor de pressão.

Tabela 7 - Valores máximos da Não Linearidade, Histerese, Repetitividade

\begin{tabular}{lc}
\hline $\mathrm{T}=20^{\circ} \mathrm{C}$ & Valor Máximo \\
\hline Não linearidade (\%FSO. BFSL) & 0,03615 \\
Histerese (\%FSO) & 0,13949 \\
Repetitividade & 0,15827 \\
Exatidão & 0,21404 \\
\hline
\end{tabular}




\subsection{Caracterização dos Transmissores Diferenciais Compensados e Calibrados}

Nesta etapa de testes caracterizaram-se dez transmissores de pressão que foram compensados nas temperaturas de $0^{\circ} \mathrm{C}$ até $80^{\circ} \mathrm{C}$ e calibrados na faixa de pressão diferencial de 0 até 25 bard e pressão de linha de 7 barg.

As temperaturas de teste foram $5^{\circ} \mathrm{C}, 27,5^{\circ} \mathrm{C}$ e $55^{\circ} \mathrm{C}$ com tempos de estabilização de 60 minutos. Realizaram-se três ciclos de medição de pressão com cinco pontos de teste: 0 , 25, 50, 75 e 100\% da amplitude da faixa de pressão diferencial. Para esta caracterização foram usados os mesmos equipamentos referenciados na seção 4.5.1 com exceção da fonte de corrente KEITHLEY a qual foi trocada pela fonte de tensão Agilent E3640A.

\subsubsection{Medições}

$\mathrm{Na}$ Tabela 8 se apresentam as correntes de saída de um dos transmissores à temperatura de $27,5^{\circ} \mathrm{C}$. Pode-se observar que os maiores erros nas leituras são obtidos para a porcentagem máxima do span de entrada.

Tabela 8 - Correntes de saída do transmissor obtidos para três ciclos de pressão

\begin{tabular}{ccccccc}
\hline & \multicolumn{2}{c}{ Ciclo 1 } & \multicolumn{2}{c}{ Ciclo 2 } & Ciclo 3 \\
\hline $\begin{array}{c}\text { Entrada } \\
\text { (\% span) }\end{array}$ & $\begin{array}{c}\text { Rampa de } \\
\text { Subida } \\
{[\mathrm{mA}]}\end{array}$ & $\begin{array}{c}\text { Rampa de } \\
\text { Descida } \\
{[\mathrm{mA}]}\end{array}$ & $\begin{array}{c}\text { Rampa de } \\
\text { Subida } \\
{[\mathrm{mA}]}\end{array}$ & $\begin{array}{c}\text { Rampa de } \\
\text { Descida } \\
{[\mathrm{mA}]}\end{array}$ & $\begin{array}{c}\text { Rampa de } \\
\text { Subida } \\
{[\mathrm{mA}]}\end{array}$ & $\begin{array}{c}\text { Rampa de } \\
\text { Descida } \\
{[\mathrm{mA}]}\end{array}$ \\
\hline 0 & 4,004 & 4,005 & 4,006 & 4,007 & 4,005 & 4,005 \\
25 & 7,999 & 8,001 & 8,001 & 8,001 & 8 & 8,001 \\
50 & 12,004 & 12,004 & 12,006 & 12,006 & 12,005 & 12,006 \\
75 & 16,017 & 16,018 & 16,016 & 16,017 & 16,018 & 16,016 \\
100 & 20,024 & 20,023 & 20,025 & 20,024 & 20,024 & 20,025 \\
\hline
\end{tabular}


Tabela 9: Média Geral dos Erros vs Pressão Diferencial vs Temperatura

\begin{tabular}{cccc} 
Temperatura $\left[{ }^{\circ} \mathrm{C}\right]$ & 5 & 27,5 & 55 \\
\hline Pressão [bar] & \multicolumn{3}{c}{ Media } \\
$\mathbf{0}$ & 0,02500 & 0,03125 & 0,0375 \\
$\mathbf{6 , 2 5}$ & 0,00938 & 0,003125 & 0,0063 \\
$\mathbf{1 2 , 5}$ & 0,03750 & 0,034375 & 0,0406 \\
$\mathbf{1 8 , 7 5}$ & 0,11562 & 0,10625 & 0,1125 \\
$\mathbf{2 5}$ & 0,15000 & 0,15 & 0,1563 \\
\hline
\end{tabular}

Na Tabela 9 e Figura 29 se mostra o comportamento da média dos erros da saída para um transmissor de pressão com relação à pressão e à temperatura, com base nos dados citados e no gráfico é observado um erro máximo de 0,156[\%FSO] que representa o valor real do TEB do transmissor.

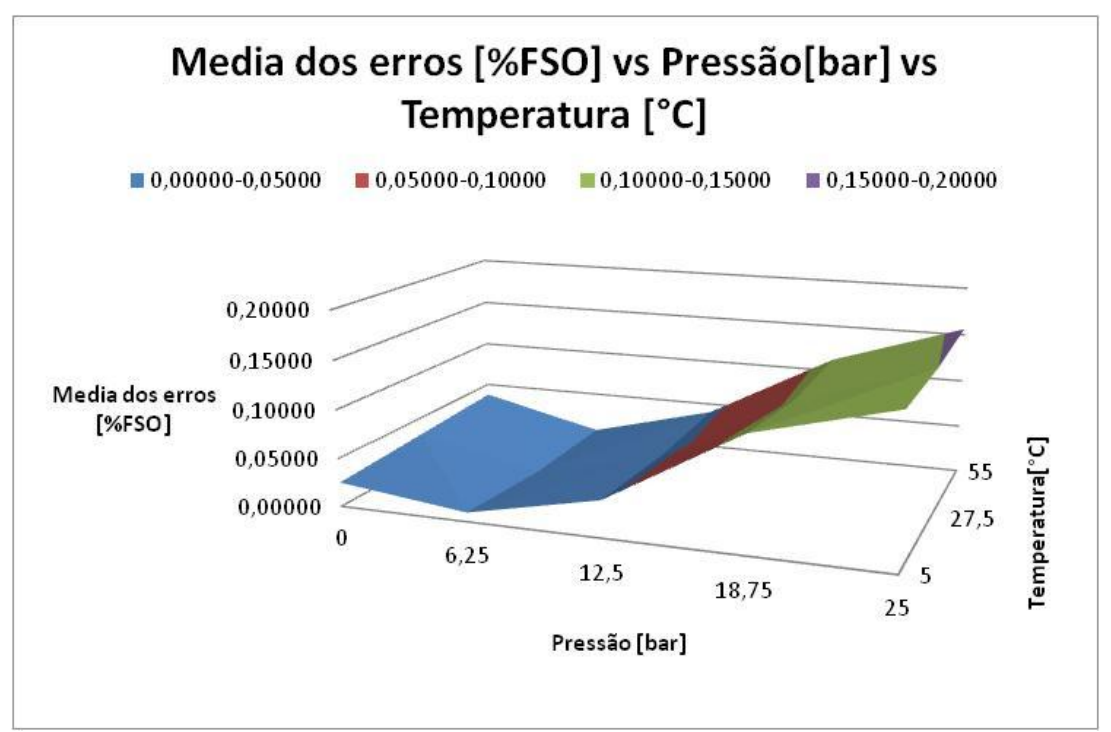

Figura 29 - Média dos erros [\%FSO] vs Pressão [bar] vs temperatura [ $\left.{ }^{\circ} \mathrm{C}\right]$.

\subsubsection{Cálculo dos Valores do TCO e TCS}

Para calcular os desvios do offset e do span em função das variações da temperatura foram medidos os valores de saída em corrente para zero e máxima pressão nas temperaturas de $5^{\circ} \mathrm{C}, 27,5^{\circ} \mathrm{C}$ e $55^{\circ} \mathrm{C}$. Estes dados se encontram na Tabela $10 \mathrm{e}$ Tabela11. O valor de TCO obtido foi de 0,0032 [\% FSO $/ 25^{\circ} \mathrm{C}$ ] e o TCS de 0,0312 $\left[\% \mathrm{FSO} / 25^{\circ} \mathrm{C}\right]$. Estes valores foram calculados usando as equações 19 e 20. 
Tabela 10: Coeficiente Térmico do Offset - TCO

\begin{tabular}{|c|c|c|c|c|}
\hline $\begin{array}{c}\text { Temperatura } \\
{\left[{ }^{\circ} \mathrm{C}\right]}\end{array}$ & $\begin{array}{c}\text { Valor Ideal da } \\
\mathbf{I}_{\text {Off set }}[\mathbf{m A}]\end{array}$ & $\begin{array}{r}\text { Valor Real da } \\
\text { I }_{\text {Offset }}[\mathbf{m A}]\end{array}$ & $\begin{array}{c}\text { Erro da } \\
\text { I }_{\text {Off set:27,5 }}{ }^{\circ}\left[\% \text { FSO }^{2}\right]\end{array}$ & $\mathrm{TCO}\left[\% \mathrm{FSO} / 50^{\circ} \mathrm{C}\right]$ \\
\hline 5 & 4 & 4,005 & $-0,0032$ & \\
\hline 27,5 & 4 & 4,006 & 0 & 0,0032 \\
\hline 55 & 4 & 4,006 & 0 & \\
\hline
\end{tabular}

Tabela 11: Coeficiente Térmico do SPAN - TCS

\begin{tabular}{ccccc}
\hline $\begin{array}{c}\text { Temperatura } \\
{\left[{ }^{\circ} \mathbf{C}\right]}\end{array}$ & $\begin{array}{c}\text { Valor Ideal da } \\
\mathbf{I}_{\text {SPAN }}[\mathbf{m A}]\end{array}$ & $\begin{array}{c}\text { Valor Real de } \\
\mathbf{I}_{\text {SPAN }}[\mathbf{m A}]\end{array}$ & $\begin{array}{c}\text { Erro da } \\
\mathbf{I}_{\text {SPAN:27,5 }} \mathbf{\circ}^{\circ}[\% \mathbf{F S O}]\end{array}$ & TCS $\left[\% \mathrm{FSO} / 50^{\circ} \mathrm{C}\right]$ \\
\hline $\mathbf{5}$ & 20 & 20,0230 & $-0,0094$ & \\
$\mathbf{2 7 , 5}$ & 20 & 20,0250 & 0,0000 & 0,0312 \\
$\mathbf{5 5}$ & 20 & 20,0201 & $-0,0312$ & \\
\hline
\end{tabular}

\subsubsection{Resultados}

O valor de TEB aproximado do transmissor de pressão utilizando a equação 21 foi de 0,055[\%FSO]. Já para ter um valor mais significativo é calculado o maior erro da saída do dispositivo. Este valor máximo que se mostra na Figura 29 é de TEB=0,156[\%FSO]. Todos os dados utilizados no cálculo do TEB se apresentam na Tabela 12.

Tabela 12- Parâmetros máximos de não linearidade, histerese e repetibilidade.

\begin{tabular}{cc}
\hline Temperatura $=27,5^{\circ} \mathrm{C}$ & $\begin{array}{c}\text { Valor } \\
\text { Máximo }\end{array}$ \\
\hline Não Linearidade (\%FSO. & 0,0418 \\
BFSL) & \\
Histerese (\%FSO) & 0,0125 \\
Repetitividade $(\% \mathrm{FSO})$ & 0,0125 \\
Exatidão $(\% \mathrm{FSO})$ & 0,0454 \\
TCO $\left(\% \mathrm{FSO} / 25^{\circ} \mathrm{C}\right)$ & 0,0032 \\
TCS $\left(\% \mathrm{FSO} / 25^{\circ} \mathrm{C}\right)$ & 0,0312 \\
TEB-Equação $21[\% \mathrm{FSO}]$ & 0,0550 \\
TEB-Grafo-[\%FSO] & 0,1560 \\
\hline
\end{tabular}




\subsection{Análise dos Resultados da Caracterização dos Sensores e dos Transmissores de Pressão Diferencial}

Dos resultados de exatidão obtidos nos sensores e transmissores diferenciais se observa uma grande melhora na exatidão do transmissor, diminuindo desde $0,2140[\% \mathrm{FSO}]$ até $0,0454[\% \mathrm{FSO}]$. Esse último resultado é devido ao processo de calibração que é realizado dentro do circuito eletrônico do transmissor de pressão diferencial.

Os valores de $\mathrm{TCO}=0,0032\left[\% \mathrm{FSO} / 25^{\circ} \mathrm{C}\right]$ e $\mathrm{TCS}=0,0312\left[\% \mathrm{FSO} / 25^{\circ} \mathrm{C}\right]$ obtidos no transmissor mostram a pouca dependência térmica do offset e do span. Estes valores foram atingidos pela eficiência do algoritmo de compensação em temperatura. $\mathrm{Na}$ tabela 13 constam as especificações do transmissor desenvolvido. Na figura 30 estão expostos os transmissores de pressão diferencial fabricados já calibrados e compensados em temperatura.

\section{Tabela 13 - Especificações do transmissor de pressão diferencial}

\begin{tabular}{ll}
\hline Alimentação & $12-36$ Volts \\
\hline Saída & $4-20 \mathrm{~mA}$ \\
Faixa de pressão diferencial & $0-25 \mathrm{bard}$ \\
Pressão de linha & $0-7 \mathrm{barg}$ \\
Sobre pressões & $70 \mathrm{barg}+, 10$ barg- \\
Faixa de temperatura compensada & $0-80^{\circ} \mathrm{C}$ \\
Exatidão & $\leq 0,05 \% \mathrm{FSO}$ \\
Total error band (do grafo) & $\leq 0,15 \% \mathrm{FSO}$ \\
Material de construção & Aço Inox 304L \\
Grau de proteção & $\mathrm{IP65}$ \\
\hline
\end{tabular}



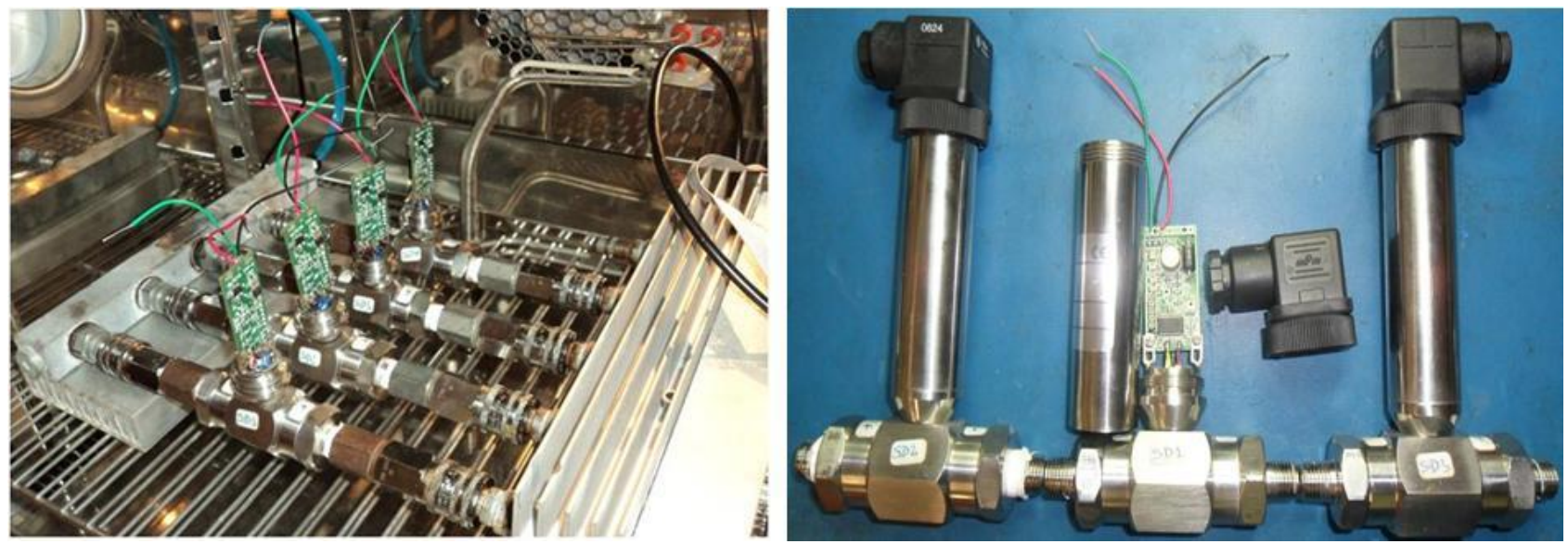

Figura 30 - Transmissores de pressão diferencial calibrados e compensados termicamente.

\subsection{Medições de Deriva do Transmissor de Pressão.}

As medições de desvio das leituras de saída do transmissor foram realizadas com base na especificação BS 6174:1982. Através destas medições foi determinada a estabilidade da corrente do transmissor de pressão a curto (Start up drift ) e longo prazos (long term drift).

\subsubsection{Medição do Desvio de Start-Up}

O objetivo do teste a seguir é estabelecer o maior desvio na saída do transmissor de pressão após ser excitado. O teste consiste em colocar o transmissor à temperatura ambiente $\left(25^{\circ} \mathrm{C}\right)$ durante 24 horas, após isto excitar o transmissor, depois aplicar uma pressão diferencial de $10 \%$ do valor do span e finalmente realizar leituras da corrente de saída para 5 minutos, 1 hora e 4 horas. Este mesmo procedimento é repetido para o 90\% da pressão diferencial de entrada (Group, 1982). O máximo desvio expresso em

porcentagem de escala plena e obtido durante todo o tempo do teste determina o desvio máximo de star-up. Este se expressa pela eq.(22).

Desvio de Start - Up $[\%$ FSO $/$ Ano $]=\frac{I_{\text {REF }}-I_{\text {ERRO MÁxIMO }}}{16} * 100$ 


\subsubsection{Resultados}

$\mathrm{Na}$ tabela 14 estão colocados os valores de desvio obtidos para um dos dez transmissores de pressão. O máximo desvio medido durante 0 teste foi de 0,025[\%FSO/Ano]. Este valor representa uma grande estabilidade da saída de corrente do transmissor a curto prazo.

Tabela 14 - Desvios de start up de um transmissor de pressão para $5 \mathrm{~min}, 1$ hora e 4 horas

\begin{tabular}{ccccc}
\hline Entrada & 5 min & 1 hora & 4 horas & Desvio Máximo \\
\hline$\%$ Span & I ref $[\mathrm{mA}]$ & $\mathrm{I}[\mathrm{mA}]$ & $\mathrm{I}[\mathrm{mA}]$ & $\% \mathrm{FSO}$ \\
$10 \%$ & 5,999 & 5,596 & 5,595 & 0,025 \\
$90 \%$ & 18,418 & 18,418 & 18,419 & 0,00625 \\
\hline
\end{tabular}

\subsubsection{Medição do Desvio de Longo Prazo}

O desvio de longo prazo foi determinado durante 10 dias com um sinal de pressão igual a $90 \%$ do span. Os dados dos sinais de entrada e saída foram registrados diariamente. A estabilidade foi determinada calculando o maior desvio nos dados durante o tempo total do teste. Este parâmetro é expresso pela eq.(23). A corrente de referência medida no primeiro dia do teste foi $I_{R E F}=18,423 m A$.

Desvio a longo tempo $[\% \mathrm{FSO} /$ Ano $]=\frac{\mathrm{I}_{\mathrm{REF}}-\mathrm{I}_{\text {ERRO MÁXIMO }}}{16} * 100$ 


\subsubsection{Resultados}

Os dados do teste de estabilidade a longo prazo estão descritos na tabela 15. O maior desvio obtido na saída de pressão durante este teste foi de 0,0625[\%FSO/Ano], o que mostra grande estabilidade na saída do dispositivo a longo prazo.

Tabela 15 - Desvios na saída de corrente do transmissor de pressão a longo prazo

\begin{tabular}{ccc}
\hline \multicolumn{3}{c}{ Condições } \\
\hline \multicolumn{3}{c}{ Temperatura: $25^{\circ} \mathrm{C}$. Umidade: $50 \%$} \\
\multicolumn{2}{c}{ Pressão Diferencial: 22,5 bard } \\
\hline Dia & $\begin{array}{c}\text { Corrente do } \\
\text { Transmissor [mA] }\end{array}$ & $\begin{array}{c}\text { Desvio } \\
\text { (\%FSO) }\end{array}$ \\
\hline 1 & 18,423 & 0 \\
2 & 18,428 & 0,03125 \\
3 & 18,429 & 0,0375 \\
4 & 18,428 & 0,03125 \\
5 & 18,433 & 0,0625 \\
6 & 18,428 & 0,03125 \\
7 & 18,427 & 0,025 \\
8 & 18,425 & 0,0125 \\
9 & 18,427 & 0,025 \\
10 & 18,418 & $-0,03125$ \\
\hline
\end{tabular}




\section{DISCUSSÃO GERAL DOS RESULTADOS}

Os resultados das medições dos sensores antes de serem compensados e calibrados apresentam dependência com a temperatura, além de possuírem características de não linearidade, repetibilidade e histerese, como era de se esperar.

O TEB de $0,055[\% F S O]$ nos transmissores diferenciais mostra a eficiência do processo de compensação e calibração em temperatura. Este valor foi obtido por cálculo numérico (Equação 21) e é uma aproximação longe da realidade, pois foi comprovado graficamente que o valor de TEB de 0,1560 [\%FSO] é consequente com a sua definição. Nas especificações do transmissor de pressão deve-se informar esta figura de mérito. Geralmente os fabricantes qualificam seu transmissor somente com o valor de exatidão.

Os valores de desvio de curto prazo de 0,025[\%FSO/Ano] e de longo prazo de 0,0625[\%FSO/Ano] mostram grande estabilidade da saída em corrente do transmissor de pressão com o tempo. Alguns fabricantes fornecem estas características para qualificar seu transmissor. 


\section{CONCLUSÕES}

- Foi especificado e selecionado o sensor de pressão diferencial piezoresistivo MDM290 da empresa Microsensor que cumpriu com as características de exatidão solicitadas na fabricação do transmissor de pressão diferencial.

- As modificações feitas na fonte de excitação do sensor de pressão diferencial permitiram adapta-lo às características de sensibilidade de entrada do chip DSSP MAX1464 mantendo a condição de consumo mínimo de 4mA do circuito eletrônico.

- O sistema de compensação e calibração desenvolvido por nosso grupo de pesquisa do LSI/EPUSP e pela MEMS permite a fabricação de transmissores de pressão com alta exatidão e confiabilidade a nível industrial.

- Foi construído um protótipo de sistema transmissor de pressão diferencial piezoresistivo de 4-20 mA composto pelas tecnologias de sensoriamento de pressão piezoresistivo, condicionamento de sinais por DSSP e algoritmos de calibração e compensação em temperatura. 


\section{REFERÊNCIAS}

ALBERT CHIOU, S. C. Thermal hysteresis and voltage shift analysis for differential pressure sensors. Sensors and Actuators A, v. 135, p. 107-112, 2005.

ARTURO HERNÁNDEZ GONZÁLEZ, J. R. B., EDGAR CHARRY RODRIGUEZ. Ajuste digital del cero y el intervalo de medida en un transmisor con salida analógica. Revista de Ingeniería Electrónica, Automatica y Comunicaciones. Habana, Cuba: Instituto Superior Politécnico “José Antonio Echeverría”. 30: 9 p. 2009.

BELTRÁN, J. R. Projeto de um Transmissor 4-20 mA, à dois fios, a partir do chip MAX1463/MAX1464 da MAXIM. MEMS Ltda. 2005

BOISVERT, J. Keep measurements on the level: Chemical Processing 2006.

BOUJAMAA, E. M. et al. A Low Power Interface Circuit for Resistive Sensors with Digital Offset Compensation. 2010 IEEE International Symposium on Circuits and Systems (ISCAS). Paris 2010.

CAVALIERI., G. P. M. How to Select Differential Pressure Transducers For Low Differential, Critical Pressure Applications. INC, S. S.

CENELEC. BS EN 61518:2001. Mating dimensions between differential pressure (type) measuring instruments and flanged-on shut-off devices up to 413 bar (41,3 MPa): BSI Group: 18 p. 2001.

. IEC 61298 - 2. Process measurement and control devices - General methods and procedures for evaluating performance: Tests under reference conditions: BSI Group 2008.

. IEC 60770-2. Transmitters for use in industrial - process control systems: Methods for inspection and routine testing: BSI Group 2011.

CHARRY, E. Verificação dos limítes térmicos do Transmissor de Pressão MEMS Ltda. São Paulo. 2007 
CHUAN, Y.; CHEN, L. The Intelligent Pressure Sensor System Based on DSP. 2010 3rd International Conference on Advanced Computer Theory and Engineering (ICACTE) 2010.

DRUCK, K. DIFFERENTIAL PRESSURE TRANSMITTER BASED ON TWO ABSOLUTE SENSORS. PD39X. Disponível em: < http://www.kellerdruck.com/home e/paprod e/39x e.asp $>$.

FIRTAT, B. et al. Differential Piezoresistive Pressure Sensor. Semiconductor Conference, 2007. CAS 2007. International, 2007, Oct. 15 2007-Sept. 17 2007. p.87-90.

GOMES, A. F. Calibração e compensação de sensores de pressão piezorresistivos. 2009. 109 (Disertação de mestrado). Departamento de Engenharia de Sistemas Eletrônicos., Escola Politécnica da Universidade de São Paulo, São Paulo.

GROUP, B. BS 6174: 1982. Specification for differential pressure transmitters with electrical outputs 1982 .

GUOXIAOBING, J. Y. Altitude and Speed Sensor with Digital Compensation Technique. IITAW '08. International Symposium on Intelligent Information Technology Application Workshops, 2008. . Shanghai 983 - 986 p. 2008.

HERRERA, C. A. M. Obtenção em larga escala de transmissores de pressão piezoresistivos de alto desempenho. 2013. 99 Mestrado (Dissertação ). Departamento de Engenharia de Sistemas Eletrônicos., Escola Politécnica da Universidade de São Paulo, São Paulo.

HONEYWELL, S. A. C. Technical Note: Pressure Sensor Glossary of Terms. 2011. Disponível em:

http://sensing.honeywell.com/pressure\%20sensor\%20glossary\%20of\%20terms th 008 200-2-en final 08jul11.pdf $>$.

INSTRUMENTATION, P. A. L. An Explanation of GP:50 Performance Specifications. Disponível em: http://www.gp50.com/pdf/Application,\%20Tech.\%20Notes\%20\&\%20Manuals/A5SL$\underline{\text { TN4.00.pdf }}>$. 
INTEGRATED, M. Designing a 4-20mA Current Loop Using the MAX1459 Sensor Signal Conditioner. 2002. Disponível em: < http://www.datasheets.org.uk/MAX1459/Datasheet-081/DASF0036323.html > .

- Creating a Ratiometric Current Excitation in Sensors Using the MAX1464

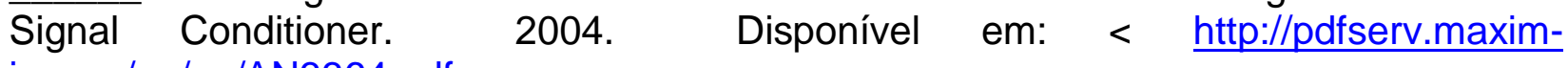
ic.com/en/an/AN3364.pdf $>$.

. MAX1464 Signal-Conditioner, Sensor Compensation Algorithm, Application Note 3649. 2005a.

. Maxim Integrated. Low-Power, Low-Noise Multichannel Sensor Signal Processor. 2005b. Disponível em: < http://datasheets.maximintegrated.com/en/ds/MAX1464.pdf $>$.

. 40V, Ultra-Low Quiescent-Current Linear Regulators in 6-Pin TDFN/8-Pin SO. 2012. Disponível em: < http://datasheets.maximintegrated.com/en/ds/MAX15006MAX15007.pdf $>$.

ISO. BS EN ISO 5167-1:2003. Measurement of fluid flow by means of pressure differerntial devices inserted in circular cross section conduit running full. General principles and requirements: BSI Group 2003.

JORGE RAMÍREZ BELTRÁN, D. H. P., EDGAR CHARRY RODRíGuEZ. Compensación térmica de la sensibilidad en sensores de presion piezorresistivos. IBERCHIP. Gaudalajara, Mexico 2002.

KATO, S. et al. High-precision silicon differential pressure sensor monolithically integrated with twin diaphragms and micro over-range protection structures. Micro Electro Mechanical Systems, 2000. MEMS 2000. The Thirteenth Annual International Conference on, 2000, 23-27 Jan 2000. p.347-351.

LTDA, M. Relatório do Transmissor de Pressão Piezoresistivo com Saída em Corrente MEMS Ltda. São Paulo. 2008

LUZ, S. F. D. Microssistema transmissor de pressão piezoresistivo de 4-20mA de alta precisão. 2006. 81 Mestrado (Dissertação). Departamento de Engenharia de Sistemas Eletrônicos, Escola Politecnica da Universidade de São Paulo, São Paulo. 
LUZ, S. F. D. Projeto e Desenvolvimento de Transmissores de Pressão Piezoresistivos com Saída em Tensão nos Padrões Industriais MEMS Ltda. São Paulo. 2008

MEMS. A MEMS - Microssistemas Integrados Híbridos de Pressão Indústria e Comércio Ltda. São Paulo, 2004. Disponível em: < http://www.mems-pressure.com/ >.

MICROSENSOR. MDM290 Piezoresistive OEM Differential Pressure Sensor. 2011. Disponível em: < http://www.microsensor.cn/micro/product info en.asp?id=98 >.

PHILIP C., J. et al. Signal Conditioner for MEMS based Piezoresistive sensor. 2010 5th International Conference on Industrial and Information Systems, ICIIS 2010. India 2010.

QING, Y.; BIN, G.; MIN, L. Differential Pressure Prediction in Air Leak Detection Using RBF Neural Network. Artificial Intelligence and Computational Intelligence (AICI), 2010 International Conference on, 2010, 23-24 Oct. 2010. p.211-213.

SAMEK, N. E.; MEI, M. Diffused silicon wet/wet differential pressure sensor and transducer for minus 100 to plus $120^{\circ} \mathrm{C}$. Sensors and Actuators A: Physical, v. 21, n. 1-3, p. 155-158, 2// 1990. ISSN 0924-4247. Disponível em: < http://www.sciencedirect.com/science/article/pii/0924424790850308 >.

SENSORS, A. A. D. Differential pressure sensing: an ambiguous term. 2008, 2008a. Disponível em: < http://www.amsys.info/sheets/amsys.en.aan505 e.pdf >. Acesso em: 2008.

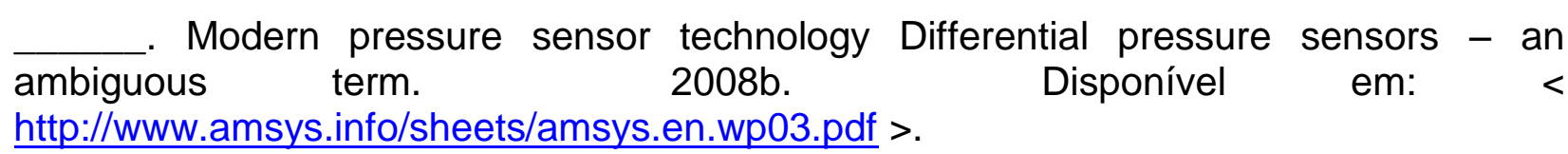




\section{ANEXOS}

ANEXo A - Esquemático do circuito eletrônico do transmissor de pressão diferencial.

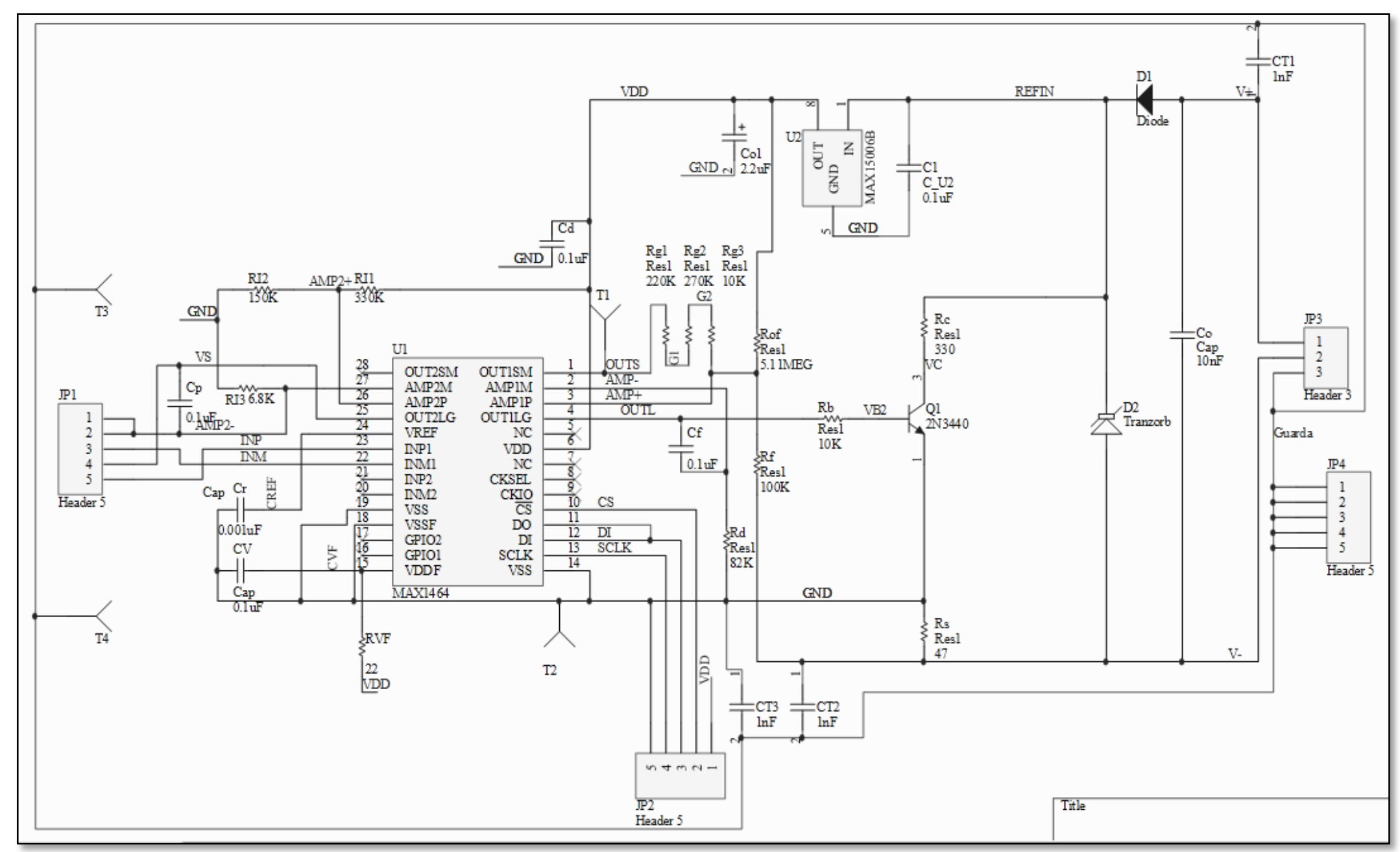


ANexo B- Publicações obtidas:

\section{Periódico}

GARCIA I. ALEJANDRO; GONZALEZ, A. H.; BELTRÁN, JORGE RAMÍREZ; MUÑOZ, RODRIGO REINA; CHARRY, R. EDGAR. Transmisor de presión diferencial de muy alta precisión y estabilidad. Revista de Ingeniería Electrónica, Automática y Comunicaciones, V. 35, P. 57-77, 2014.

\section{Congresso}

GARCIA I. ALEJANDRO ; GONZALEZ, A. H. ; BELTRÁN, Jorge Ramírez ; MUÑOZ, Rodrigo Reina ; CHARRY, R. EDGAR. Transmissor de pressão diferencial de altíssima precisão e confiabilidade. In: 17 Congresso Internacional e Exposição De Automação, Sistemas e Instrumentação, 2013, São Paulo. Brasil Automation ISA. 